\title{
High-temperature shear zone formation in Carrara marble: The effect of loading conditions
}

\author{
Livia Nardinia, b, ", Erik Rybackia, Maximilian J. E. A. Döhmann ${ }^{b, c}$, Luiz F. G. Morales ${ }^{d}$, Sascha Brune ${ }^{b, c}$, Georg Dresen $^{\mathrm{a}, \mathrm{b}}$

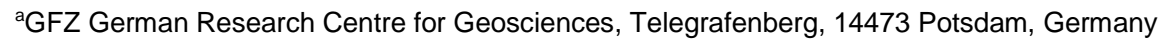 \\ bUniversität Potsdam, Institut für Erd- und Umweltwissenschaften, 14476 Potsdam-Golm, Germany \\ 'GFZ German Research Centre for Geosciences, 14473 Potsdam, Germany \\ ¿ScopeM, ETH Zürich, 8093 Zürich, Switzerland \\ *Corresponding author (nardini@gfz-potsdam.de)
}

\section{Abstract}

Rock deformation at depths in the Earth's crust is often localized in high temperature shear zones occurring at different scales in a variety of lithologies. The presence of material heterogeneities is known to trigger shear zone development, but the mechanisms controlling initiation and evolution of localization are not fully understood.

To investigate the effect of loading conditions on shear zone nucleation along heterogeneities, we performed torsion experiments under constant twist rate (CTR) and constant torque (CT) conditions in a Paterson-type deformation apparatus. The sample assemblage consisted of cylindrical Carrara marble specimens containing a thin plate of Solnhofen limestone perpendicular to the cylinder's longitudinal axis. Under experimental conditions $\left(900^{\circ} \mathrm{C}, 400 \mathrm{MPa}\right.$ confining pressure), samples were plastically deformed and limestone is about 9 times weaker than marble, acting as a weak inclusion in a strong matrix. CTR experiments were performed at maximum bulk shear strain rates of $\sim 2^{*} 10^{-4} \mathrm{~s}^{-1}$, yielding peak shear stresses of $\sim 20 \mathrm{MPa}$. CT tests were conducted at shear stresses of $\sim 20 \mathrm{MPa}$ resulting in bulk shear strain rates of $1-4^{*} 10^{-4} \mathrm{~s}^{-1}$. Experiments were terminated at maximum bulk shear strains of $\sim 0.3$ and 1.0 .

Strain was localized within the Carrara marble in front of the inclusion in an area of strongly deformed grains and intense grain size reduction. Locally, evidences for coexisting brittle deformation are also observed regardless of the imposed loading conditions. The local shear strain at the inclusion tip is up to 30 times higher than the strain in the adjacent host rock, rapidly dropping to 5 times higher at larger distance from the inclusion. At both investigated bulk strains, the evolution of microstructural and textural parameters is independent of loading conditions. Our results suggest that loading conditions do not significantly affect material heterogeneity-induced strain localization during its nucleation and transient stages.

\section{Keywords}

Shear zones, localization, marble, torsion, loading conditions 


\section{Introduction}

Localization of deformation in the deep crust and mantle is a key mechanism involved in the formation of tectonic plates and mountain belts on our planet (Tackley, 2000; Schubert et al., 2001; Bercovici and Karato, 2002; Bercovici, 2003; Regenauer-Lieb \& Yuen, 2003;

Regenauer-Lieb and Yuen, 2004). Therefore, the knowledge of how deformation is accommodated at plate boundaries and orogenic belts requires the understanding of physical processes that govern localized deformation in the ductile regime and its persistence over geological times.

A multitude of mechanisms have been proposed to be responsible for nucleation of localized deformation in the middle to lower crust, under the generally accepted premise that a dynamic (positive) feedback mechanism is required to induce thermo-mechanical perturbances in otherwise homogeneously deforming mediums (Bercovici, 1996, 1998; Bercovici and Karato, 2002; Regenauer-Lieb \& Yuen, 2003). Grain size reduction by dynamic recrystallization (e.g. Montési \& Hirth, 2003; Kilian et al., 2011; Platt \& Behr, 2011b), fluid influx inducing metamorphic reactions (e.g. Fusseis \& Handy, 2008), development or pre-existence of a crystallographic preferred orientation (e.g. Michibayashi \& Mainprice, 2004; Tommasi et al., 2009), ductile fracturing (e.g. Handy and Stünitz, 2002; Dimanov et al., 2007; Rybacki et al., 2008; Menegon et al., 2013) and the presence of material heterogeneities (e.g. Rybacki et al., 2014) are only some of the mechanisms that were recognized in the field and through experimental work as factors causing rheological weakening and subsequent ductile localization of strain (see Burlini \& Bruhn, 2005 for a review). A number of experimental investigations at constant strain rate have failed to produce notable localization in monophase materials in the ductile regime even at very high strains (e.g. Bystricky et al., 2000; Ter Heege et al., 2002; Barnhoorn et al., 2004). Some observations suggest that constant stress loading conditions appear to initiate localization in highly deformed olivine aggregates (Hansen at al., 2012). However, the effects of material properties and boundary conditions on the mechanical and microstructural evolution associated with strain localization and weakening are not yet understood and only a few experimental studies exist at present. So far, the effect of the imposed loading conditions on the efficiency of localization within homogeneous materials has largely been investigated in theoretical models (Fressengeas \& Molinari, 1987; Leroy \& Molinari, 1992; Paterson, 2007) but experimental studies of ductile localization induced by some of the aforementioned mechanisms of rheological weakening have not yet been performed.

In nature, calcite rich rocks are known to be preferential lithologies for the localization of deformation in the high temperature ductile regime and to lead to the formation of large scale shear zones where up to tens of kilometres of displacement are accommodated (e.g. the 
Glarus Thrust in the Helvetic Nappe, Groshong et al. 1984; Herwegh \& Kunze, 2002;

Ebert et al., 2007). Calcite and natural carbonate materials have been extensively studied in the ductile regime both experimentally (e.g. Schmid et al., 1980; Rutter, 1994, 1995, Pieri

et al., 2001a, 2001b; Barnhoorn et al., 2004) and in the field (Schmid et al., 1981;

Bestmann et al., 2000; Rogowitz et al., 2014, 2016), so that the calibration of mechanical, microstructural and textural data for calcite at different deformation conditions is well established.

In this contribution, we experimentally investigate the effects of different loading conditions (constant stress versus constant strain rate) on the nucleation and evolution of heterogeneity-induced high temperature shear zones in a carbonate system.

\section{Experimental setup}

The torsion experiments presented here were carried out on mono-mineralic calcite aggregates consisting of Carrara marble with elongated Solnhofen limestone inclusions. A thin $(0.75 \mathrm{~mm})$ circle segment of Solnhofen limestone with an arc length of about $11.8 \mathrm{~mm}$ was inserted in a saw-cut slot in a hollow cylinder $(10 \mathrm{~mm}$ height, $15 \mathrm{~mm}$ outer diameter, 6.1 $\mathrm{mm}$ inner diameter) of Carrara marble. Ceramic glue was used to fill up the possible gaps in the slot. Two alumina spacers (for protection of the pistons in the deformation apparatus) and a solid gold cylinder inserted in the inner borehole of the sample completed the setup (Fig. 1).

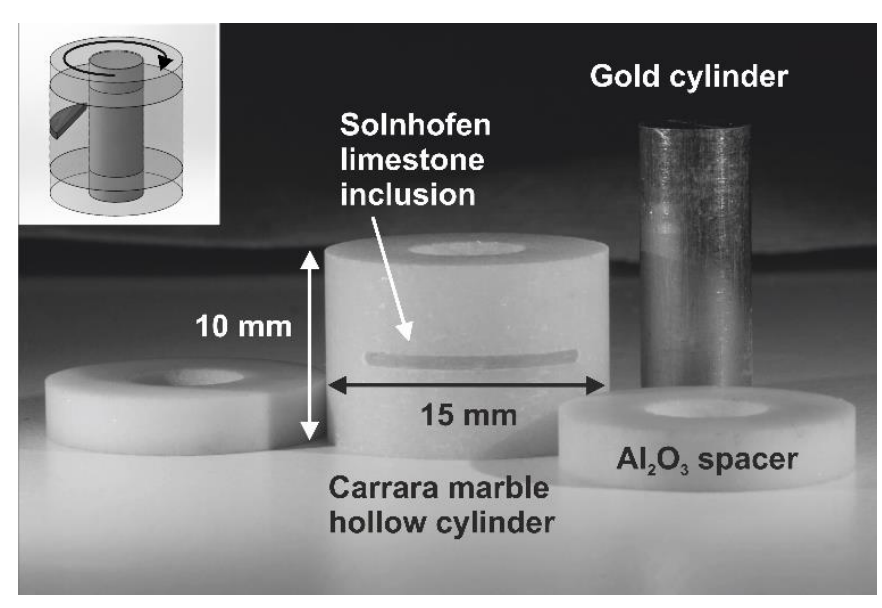

Fig. 1: Elements of the sample assembly. In the small inset, the setup prior to insertion in the copper jacket; indicated is the direction of the applied torsion.

The hollow cylinder configuration was preferred as it guarantees a relatively homogeneous distribution of shear stress within the sample (Paterson and Olgaard, 2000). Carrara marble is a largely used material in experimental rock deformation due to its exceptional purity (> 99\% $\mathrm{CaCO}_{3}$ ) and low to no initial porosity (Rutter, 1995; Pieri et al., 2001a and 2001b; Ter Heege et al., 2002; Barnhoorn et al., 2004; De Bresser et al., 2005). The undeformed 
marble shows a uniform grain size distribution with an average grain size in the order of the hundreds of microns ( $150 \mu \mathrm{m}$ ), abundant triple junctions, straight grain boundaries and a quasi-uniform crystallographic orientation distribution (see section 4.3 and figures therein). Twinned crystals are present, but the twins are extremely thin $(<5 \mu \mathrm{m})$, straight and not pervasive. Solnhofen limestone is an extremely fine grained ( $\sim \mu \mathrm{m}$ average grain size) almost pure calcite rock (more than 97 wt\% calcite, Rutter, 1972). As a consequence of a large difference in initial grain size, Solnhofen limestone is up to 9 times weaker than Carrara Marble at the imposed experimental conditions of $900^{\circ} \mathrm{C}$ temperature and $400 \mathrm{MPa}$ confining pressure (e.g. Rybacki et al., 2014), inducing a strong viscosity contrast between the two materials in our experimental setup.

Experiments were performed in a Paterson-type gas deformation apparatus equipped with a torsion actuator (Paterson and Olgaard 2000). Prior to experimental runs, the samples were inserted into copper jackets of $\sim 0.2 \mathrm{~mm}$ thickness (to isolate them from the gas confining pressure medium) the strength of which is accounted for in the evaluation of the mechanical data. The samples were first pressurized to $400 \mathrm{MPa}$, followed by heating at a rate of $\sim 30$ ${ }^{\circ} \mathrm{C} / \mathrm{min}$ up to the desired temperature of $900^{\circ} \mathrm{C}$ (with accuracy of $\pm 2{ }^{\circ} \mathrm{C}$ along the sample axis). After test termination, load was maintained constant during cooling (at equal rate to the heating phase) to preserve deformation microstructures and to reduce the amount of static recovery occurring within the samples.

Following Paterson and Olgaard, 2000, the measured torque $M$ was converted to maximum shear stress $\tau$ at the periphery of the sample cylinder according to the equation:

$$
\tau=\frac{4 M\left(3+\frac{1}{n}\right)}{\pi} \frac{D_{0}^{\frac{1}{n}}}{D_{0}^{3+\frac{1}{n}}-D_{i}^{3+\frac{1}{n}}}
$$

where $D_{0}$ and $D_{i}$ are the external and internal diameter of the cylinder, respectively. Measured displacement rate $\dot{\theta}$ in radians is converted to maximum shear strain rate $\dot{\gamma}$ according to the following:

$$
\dot{\gamma}=\frac{D_{0} \dot{\theta}}{2 l}
$$

where $D_{0}$ is the external diameter of the sample and $l$ is the length of the cylindrical specimen.

\section{Analytical methods}

Thin sections were produced for microstructural and textural investigations. To ensure the analyses were carried out on the portion of the sample that experienced the highest (measured) strain, the sections were cut tangentially to the outer rim and parallel to the 
longitudinal axis of the cylinders (after Paterson \& Olgaard, 2000). The thin sections were polished in two steps, first with diamond paste up to $0.25 \mu \mathrm{m}$ grain size followed by 2 hours of chemical-mechanical polishing with an alkaline solution of colloidal silica. To investigate the crystallographic orientation of the calcite grains, all thin sections were examined with electron back-scattered diffraction (EBSD) technique on a FEI Quanta 3D FEG dual beam machine equipped with an EDAX-TSL Digiview IV EBSD detector and the TSL software OIM 5.31 for the acquisition of diffraction patterns. EBSD analyses were performed on uncoated samples under low vacuum conditions $\left(10 \mathrm{~Pa} \mathrm{H}_{2} \mathrm{O}\right)$ using an accelerating voltage of $15 \mathrm{kV}$ and beam current of $8 \mathrm{nA}$ in variable working distances between 13 and $16 \mathrm{~mm}$.
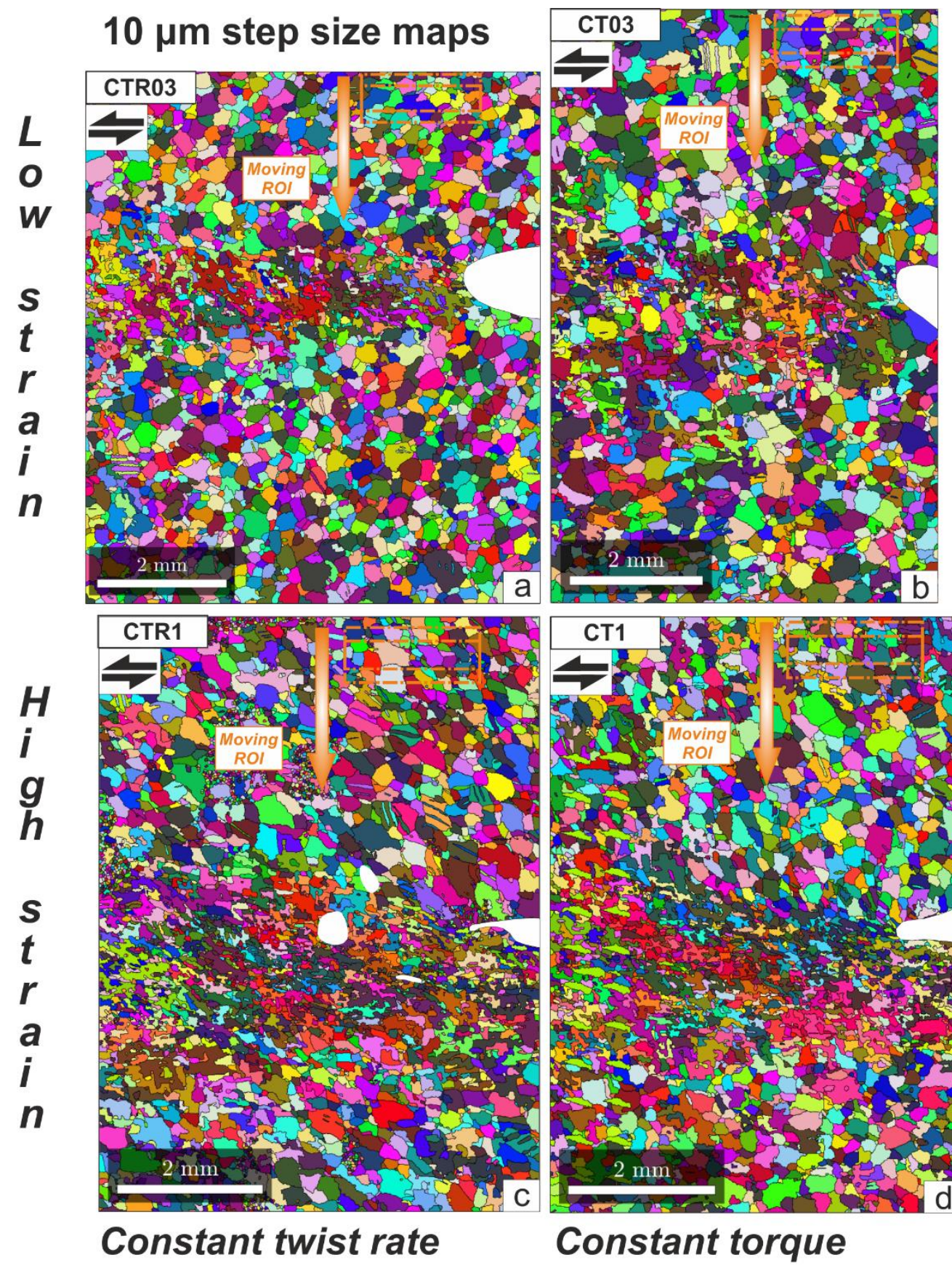

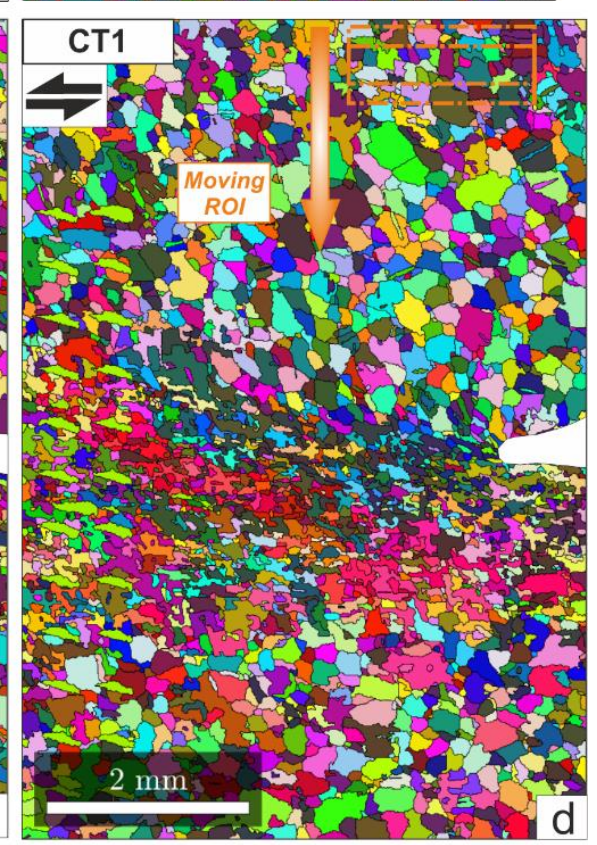

Constant torque 
Fig. 2 a-d: $10 \mu \mathrm{m}$ step size orientation maps from EBSD data, used for the construction of grain size profiles across the thin sections (in orange, the partially overlapping moving region of interest, $\mathrm{ROI}$ ). In a and $\mathrm{c}$ the constant twist rate samples and in $\mathrm{b}$ and $\mathrm{d}$ the constant torque ones.

Crystallographic orientation mapping was performed systematically in all studied samples using two different step sizes (10 $\mu \mathrm{m}$ and $3.5 \mu \mathrm{m}$ ). The coarser step size map was used to map the orientations of the whole sample and for the construction of mean grain size profiles across the thin sections (top to bottom; orange rectangles in Fig. 2a-d). The fine step size mapping was limited to the area in front of the limestone inclusion, where deformation localizes (Fig. 3a-d); these maps were used for the study of shape descriptors (section 4.4) and their variations within regions in and outside of the localized zone in front of the inclusion (red rectangles in Fig. 3a-d).
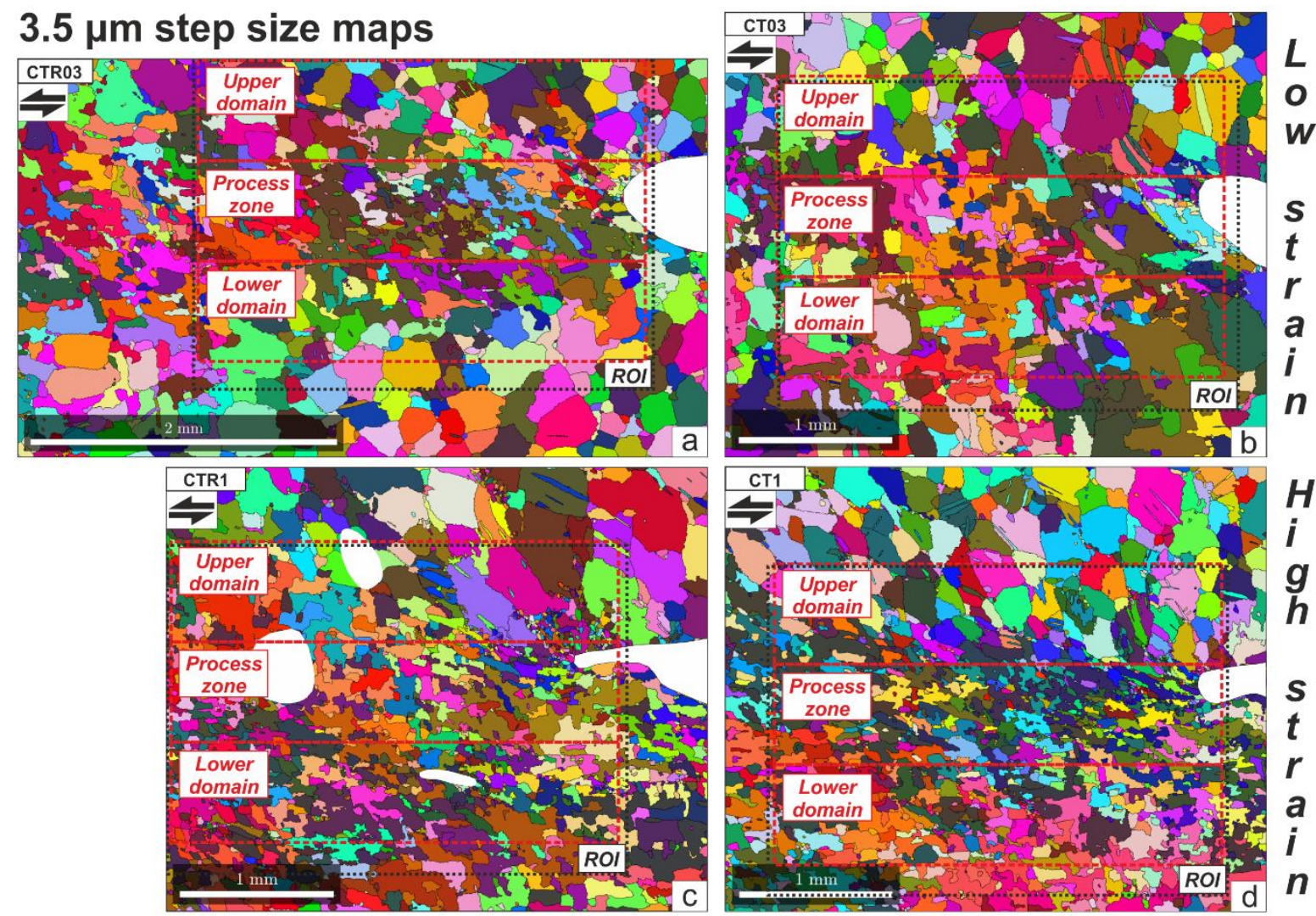

\section{Constant twist rate}

\section{Constant torque}

Fig. 3 a-d: Location of regions of interest for different data extractions on $3.5 \mu \mathrm{m}$ step size orientation maps from EBSD data. Two types of areas (red and black) are considered for different calculations. In a and c the constant twist rate samples, in $b$ and $d$ the constant torque ones.

Clean-up of the raw data was carried out using the TLS software OIM Analysis 7.3, with standardization of the confidence index $(\mathrm{Cl})$ within grains. Individual grains were defined using the following parameters: minimum grain tolerance angle of $10^{\circ}$ (misorientation angle between neighbouring points) and a minimum of 10 indexed points per grain. Following this step, a Cl correlation between neighbour points was applied to the datasets, considering a $\mathrm{Cl}$ 
of 0.1 , meaning that data points with $\mathrm{Cl}<0.1$ are reassigned the orientation and $\mathrm{Cl}$ of the neighbour data point with the highest $\mathrm{Cl}$ within individual grains.

To identify very small (dynamically recrystallized) grains and their spatial distribution, a minimum of 5 indexed points per grain criterion (to reduce the loss of small grains by interpolation and smoothing) was used in the finer stepping size maps within a region of interest (Fig. 3a-d, black rectangles). Unless otherwise specified, grain sizes are expressed as equivalent diameter (diameter of a circle of equivalent area to the grain).

Calculations on the EBSD data were performed using the MTEX 4.3.2 toolbox for Matlab (Hielscher and Schaeben, 2008; Bachmann et al., 2010). Orientation distribution function and pole figure contouring were calculated using a Gaussian half-width of $10^{\circ}$ and a maximum harmonic expansion factor of 32 .

Grain size evolution across the samples (see section 4.4) was investigated using the coarser EBSD maps (10 $\mu \mathrm{m}$ step size). A moving, partially overlapping (one third of the vertical size) window of size $1.85 \times 0.5 \mathrm{~mm}$ (Fig. 2a-d) was used to extract data along a profile parallel to the longitudinal axis of the sample cylinder located directly in front of the limestone inclusion in the Carrara marble. Grains transected by the boundary of the moving window were excluded from the calculations. For each window, we estimated the average grain size using the RMS (root mean square) value of the distribution.

To characterize grain shape evolution within the area covered by the finer step size maps (section 4.4), two shape descriptors were considered. First, the inverse aspect ratio (according to the definition of the MTEX toolbox, Hielscher and Schaeben, 2008: IAR $=\frac{w}{l}$, $w$ and $l$ being the width and length of the particle, respectively) and secondly a variation of the classical circularity shape factor, defined as follows:

$$
\operatorname{Circ}=\frac{4 \pi A}{P^{2}}
$$

150 where $A$ is the area and $P$ the perimeter of a grain (Heilbronner and Barrett, 2014). Both shape descriptors assume values between 1 and 0 , where the former represents a circle (maximum IAR) with smooth surfaces (maximum circularity) and the latter is characteristic of an infinitely non-circular shape (minimum IAR) with infinitely rough surfaces (minimum circularity).

155 For the study of shape descriptors a grain size filtering was applied to the datasets in order to remove small grains produced by dynamic recrystallization, which are expected to approach the ideal circular shape at the time of formation. The size filter was set to $20 \mu \mathrm{m}$, which is the average grain size of dynamically recrystallized grains determined by optical microscopy. 
Six transmission electron microscopy foils $(0.15 \mu \mathrm{m}$ in thickness) from a single thin section (sample CTR03) were prepared using the focused ion beam technique (e.g. Wirth, 2005) and subsequently inspected with transmission electron microscopy (TEM) on a FEI Tecnai G2 F20 X-Twin TEM for the calculation of dislocation densities (see section 4.5).

\section{Results}

\subsection{Mechanical data}

165 We present the results from four experiments, two of which were run at constant twist rate and two at constant torque conditions (CTR and CT, respectively, equivalent to constant strain rate and constant stress) in the torsion setup of a Paterson-type gas deformation apparatus. The final bulk strains reached in the experiments are $\gamma \sim 0.3$ and $\gamma \sim 1$, respectively, for both loading configurations. Experimental conditions for the four samples presented here are shown in Table 1.

\begin{tabular}{|c|c|c|c|c|c|c|c|}
\hline $\begin{array}{c}\text { Sample } \\
\text { name }\end{array}$ & $\mathrm{P}(\mathrm{MPa})$ & $\mathrm{T}\left({ }^{\circ} \mathrm{C}\right)$ & Test type & $\dot{\gamma}, \mathrm{s}^{-1}$ & $\tau, \mathrm{MPa}$ & $\gamma_{\max }$ & $\gamma_{s e c}$ \\
\hline CTR03 & 400 & 900 & Torsion & $1.8 \times 10^{-4}$ & 20.1 & 0.293 & 0.2 \\
\hline CT03 & 400 & 900 & Torsion & $\begin{array}{c}2.1-2.4 x \\
10^{-4}\end{array}$ & 19.8 & 0.29 & 0.2 \\
\hline CTR1 & 400 & 900 & Torsion & $1.9 \times 10^{-4}$ & $\begin{array}{l}19.7- \\
17.6\end{array}$ & 0.99 & 0.68 \\
\hline CT1 & 400 & 900 & Torsion & $\begin{array}{c}1.2-4.0 x \\
10^{-4}\end{array}$ & $\begin{array}{l}18.8- \\
18.4\end{array}$ & 0.94 & 0.65 \\
\hline
\end{tabular}

Table 1: Experimental conditions for the four samples here presented. CTR is constant twist rate (strain rate) experiments, CT constant torque (stress), $\dot{\gamma}$ is shear strain rate (in $\mathrm{s}^{-1}$ ), $\gamma_{\max }$ is maximum bulk shear strain and $\gamma_{s e c}$ is the local shear strain in a section of radius $r_{\text {sec }}$.

In CTR experiments (Fig. 4a), shear stress is plotted against bulk shear strain, while for CT experiments (Fig. 4b), shear strain rate is plotted versus bulk shear strain in semi-logarithmic scale. In constant twist rate experiments, measured peak shear stresses of about $19 \mathrm{MPa}$ at the periphery of the samples are reached at low values of bulk shear strain $(\gamma \sim 0.15)$, after which mechanical softening occurs and a gradual weakening of the samples can be observed up to the maximum bulk strains reached, $y=0.29$ for sample CTR03 and $y=0.99$ for sample CTR1. For constant torque experiments, the applied torque was set so that the shear stress at the periphery of the samples is $\sim 19 \mathrm{MPa}$, similar to the maximum stress measured in constant twist rate tests. Bulk shear strain rates first decreased rapidly due to elastic loading, followed by a gradual decrease up to a minimum at $\gamma \sim 0.1-0.2$.

Subsequently, strain rates increased corresponding to mechanical weakening of the samples 

СT03 compared to CT1 is related to the higher initially applied stress (Tab. 1).

a)

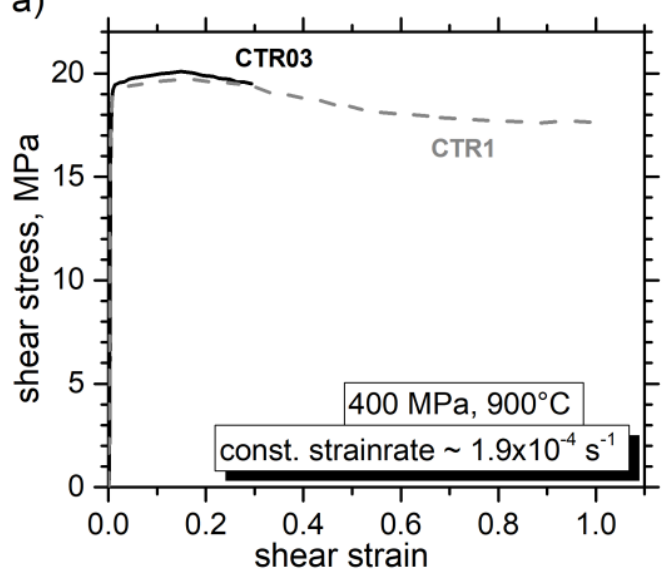

b)

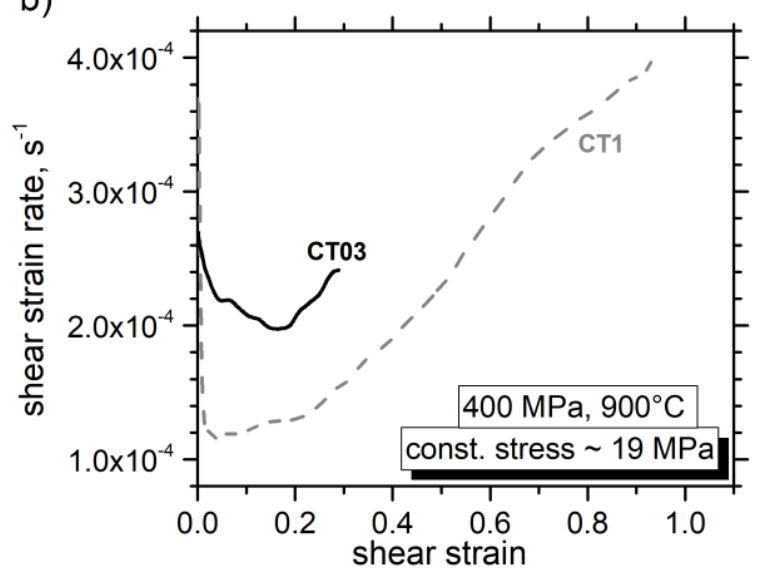

Fig. $4 a$ and b: Mechanical shear stress-strain curves of torsion experiments performed at constant twist rate (a) and constant torque (b).

\subsection{Strain localization}

In order to quantify the local distribution of shear strain within the samples, passive strain markers were applied to the copper jackets prior to the experimental runs (except for sample CTR03). A grid of evenly spaced straight lines, parallel to the cylinder axis, was carved in the copper jacket (Fig. 5; denser spacing is corresponding to the area where the inclusion is located) and recovered after the experiments. The locally imposed shear strain is estimated from the angular deflection of the originally straight lines. After deformation, the distribution of those lines is clearly heterogeneous and reflects the partitioning of strain between the limestone inclusion and the Carrara marble.

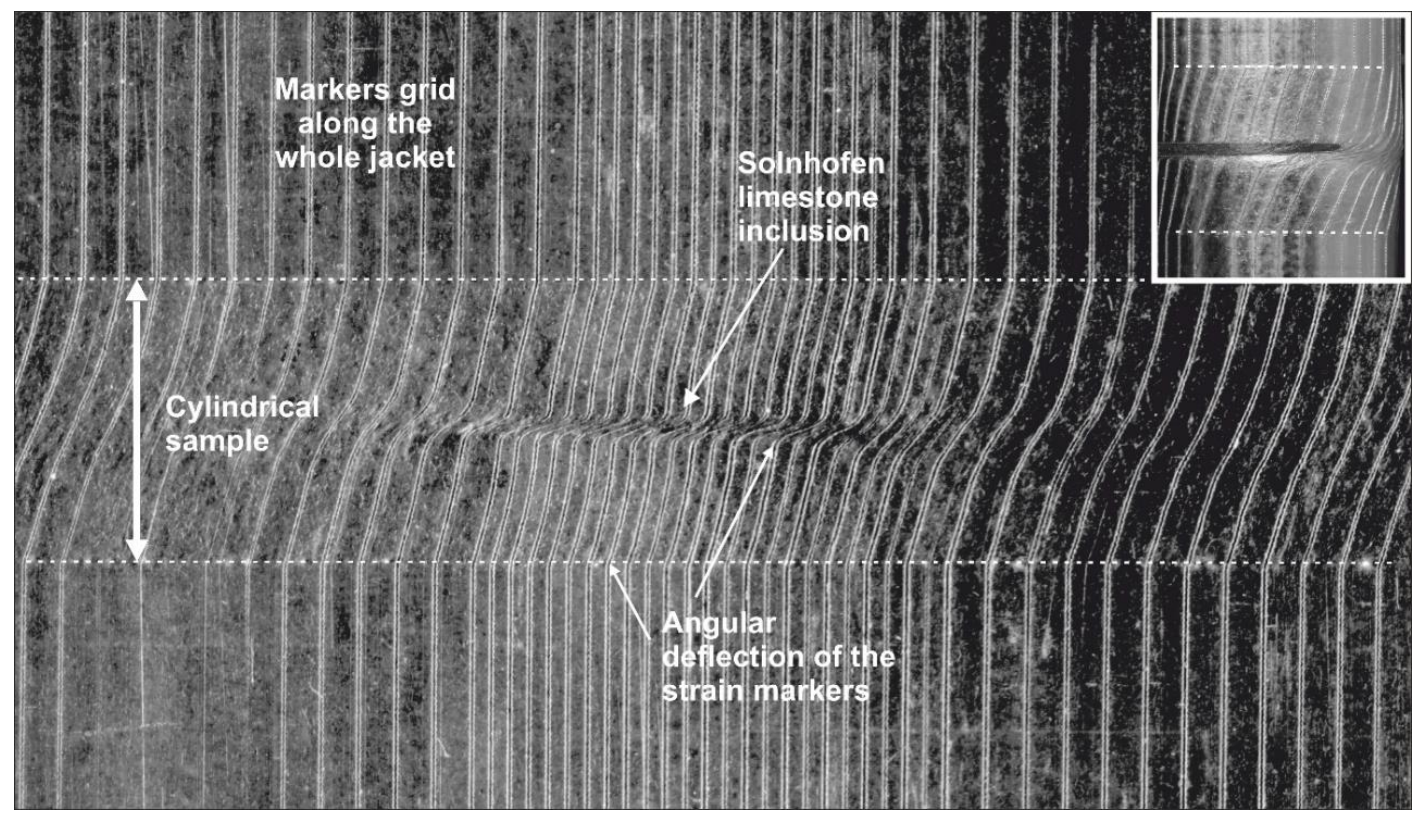

Fig. 5: Example of the strain markers grid as applied on the copper jacket, recovered after the experimental run. 
In particular, a substantial difference in shear strain can be observed between the region directly in front of the Solnhofen inclusion and the surrounding matrix, indicative of ongoing strain localization within the Carrara marble itself, related to the presence of a material heterogeneity.

(a)

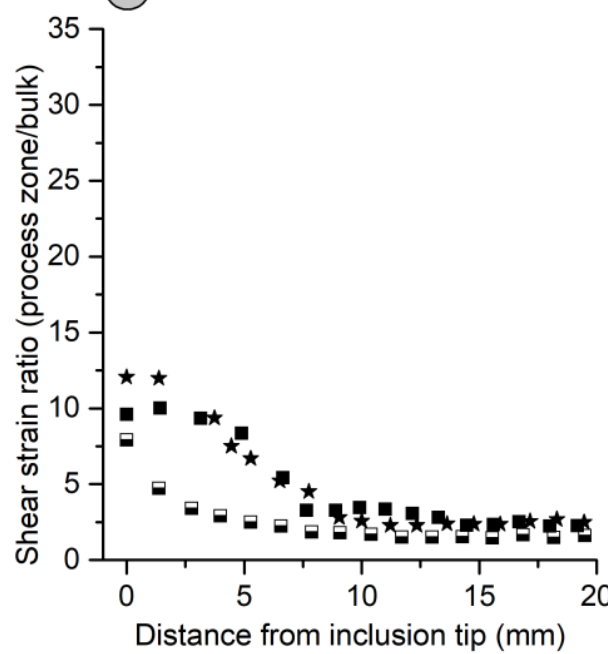

(b)

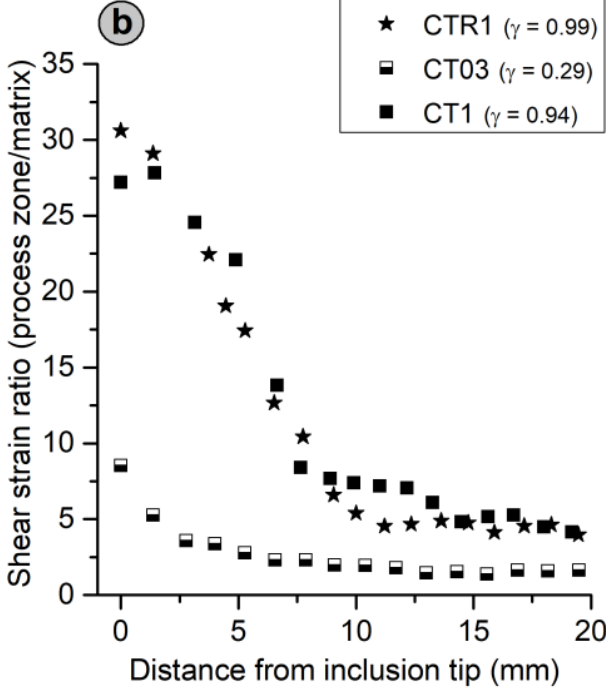

Fig. $6 a$ and $b$ : Local shear strain evolution with distance from inclusion tip. a) Normalized local shear strain (Yprocess zone / Ybulk); b) local shear strain ratio, Yprocess zone / Ymatrix.

Local shear strains are calculated for this area of incipient localized deformation (named hereafter the process zone) and for the less deformed matrix at some distance from the inclusion tip. A strongly localized shear strain in front of the inclusion is observed (up to a factor $~ 12$ compared to the imposed bulk strain), rapidly decaying to background strain level with distance $(\sim 10 \mathrm{~mm})$ from the inclusion (Fig. 6a). The degree of strain localization (i.e. the ratio between local to bulk shear strain) is not substantially different between the two loading conditions of constant twist rate or constant torque (cf., samples CTR1 and CT1, respectively), especially when one considers the large uncertainty in the calculated local strains when the angular deflection is large and the measurements become less accurate (a $3^{\circ}$ variation can lead to a difference in $\gamma$ of 10 ).

In Figure $6 \mathrm{~b}$ the local strain measured in the process zone is normalized to that of the surrounding, less deformed matrix, plotted against distance from the inclusion tip. The localization of deformation in the process zone with respect to the adjacent matrix is higher by a factor 2-3 than with respect to the bulk strain (Fig. 6a). Clearly, the degree of localization is further developed at higher total bulk strain (samples CTR1 and CT1, as opposed to sample CT03). Again, no substantial difference is noticed between constant stress and constant strain rate samples. 
In composite micrographs from optical microscopy images we typically observe an area of intense grain size reduction and highly deformed grains in the Carrara marble matrix, close to the Solnhofen limestone inclusion (Fig. 7a-b and f-g). In contrast, the surrounding matrix region remains almost undeformed, and equant grains display similar characteristics to the undeformed Carrara marble (Fig. 7k-m). Note that the bulk shear strain indicated on the micrographs refers to the maximum measured shear strain. Approximate local shear strain $\gamma_{s e c}$ within a section of the sample cylinder cut at a radius $r_{s e c}$ is about $30 \%$ lower (Tab. 1), determined by:

$$
\gamma_{\text {sec }}=\frac{r_{s e c}}{r} \gamma_{\max }
$$

235 In all micrographs the Solnhofen limestone inclusion is located on the right side, showing at higher strain stronger distortion from the original undeformed rectangular shape (Fig. 1). 


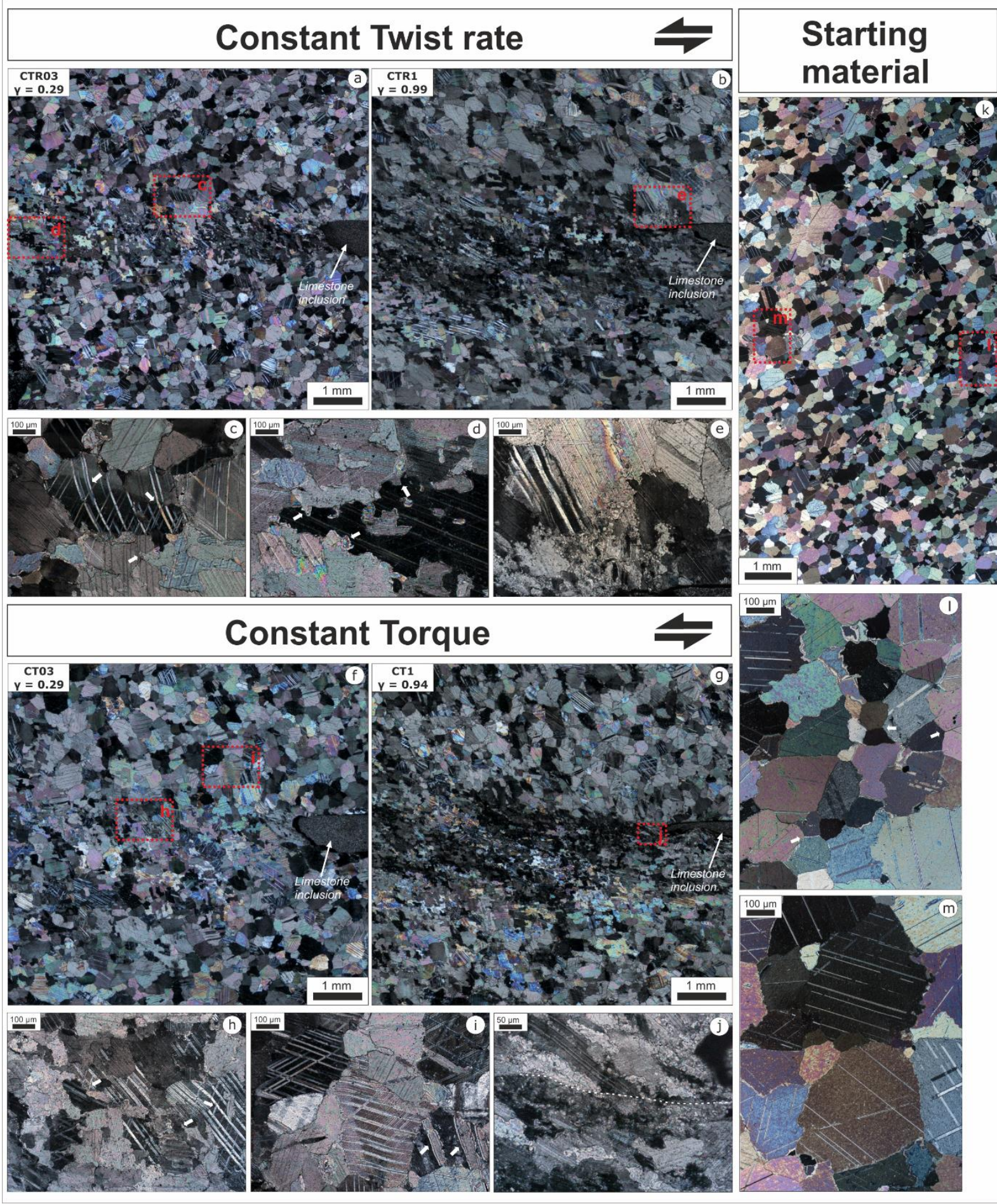

Fig. 7 a-m: Optical micrographs of 5 thin sections (four from the experimental runs and one from the undeformed starting material), and small insets (c-e, h-j and I,m) displaying details of the microstructures; insets $c$ and $d$ are areas of sample CTR03, e is from sample CTR $1, f$ and $g$ from CT03 and $h$ from CT1. The undeformed starting material displays a homogeneous microstructure with little to no stored strain, large equant grains and abundance of triple junctions ( $\mathrm{l})$; twin sets are thin and straight $(\mathrm{m})$. In the overview micrographs of the deformed samples (a$b$ and $f-g$ ), a strongly inhomogeneous distribution of strain can be observed, with the incipient (CTR03 and CT03) and progressive (CTR1 and CT1) formation of an area of intensely localized deformation in front of the inclusion.

In the low strain samples (CTR03 and CT03, $y \sim 0.3$; Fig. 7a and f) the process zone, represented by the area of intense localized deformation in front of the inclusion tip, is 
characterized by intense twinning, with grains often developing two distinct sets of twins oriented at $\sim 60^{\circ}$ to each other (Figs. $7 \mathrm{c}$ and $7 \mathrm{~h}-\mathrm{i}$ ). Bending and tapering of twin sets can be observed in several cases (Fig. 7c and i). Undulose extinction and lobate grain boundaries (Figs. 7c-d and $7 \mathrm{~h}-\mathrm{i}$ ) are pervasive, indicating active crystal plasticity and intracrystalline deformation mostly by dislocation glide. Grain size reduction by dynamic recrystallization is incipient in the process zone of the low strain samples. Qualitatively, the microstructures of the two samples deformed to similar strain at different boundary conditions show similar characteristics.

The most striking feature characterizing the process zone of the high bulk shear strain 255 samples (CTR1 and $\mathrm{CT1}, \mathrm{y} \sim 1$; Fig. 7b and $\mathrm{g}$ ) is the intense grain size reduction due to pervasive dynamic recrystallization (Fig. $7 e$ and j), frequently resulting in core-and-mantle structures. The abundance of undulose extinction, lobate grains boundaries and subgrains similar in size to the recrystallized grains suggest prevailing subgrain rotation recrystallization with subordinate contributions of grain boundary migration recrystallization (Guillope and Poirier, 1979; Drury and Urai, 1989). At high strain twinning is less prominent. Grain boundaries are typically sutured and curved indicating grain boundary migration. We observe a shape preferred orientation of the deformed elongate grains resulting in a foliation gently inclined to the shear plane (Fig. $7 \mathrm{~b}$ and g). Similar to the low strain samples, the main microstructural features are similar in samples deformed in both loading conditions applied to the high strain samples.

Close to the inclusion tip incipient brittle deformation is visible in all samples (Fig. 8). Scanning electron microscope (SEM) images combined with optical close-ups reveal cracks preferentially located at grain boundaries and small voids ahead of the inclusion tip. Small, mostly tensile cracks oriented parallel to the direction of $\sigma_{1}$ are visible in the low strain constant twist rate sample (Fig. 8a-b). In the equivalent strain constant torque sample, a single shear fracture propagating from the tip of the weak limestone inclusion is formed within the host marble (Fig 8c-d). 

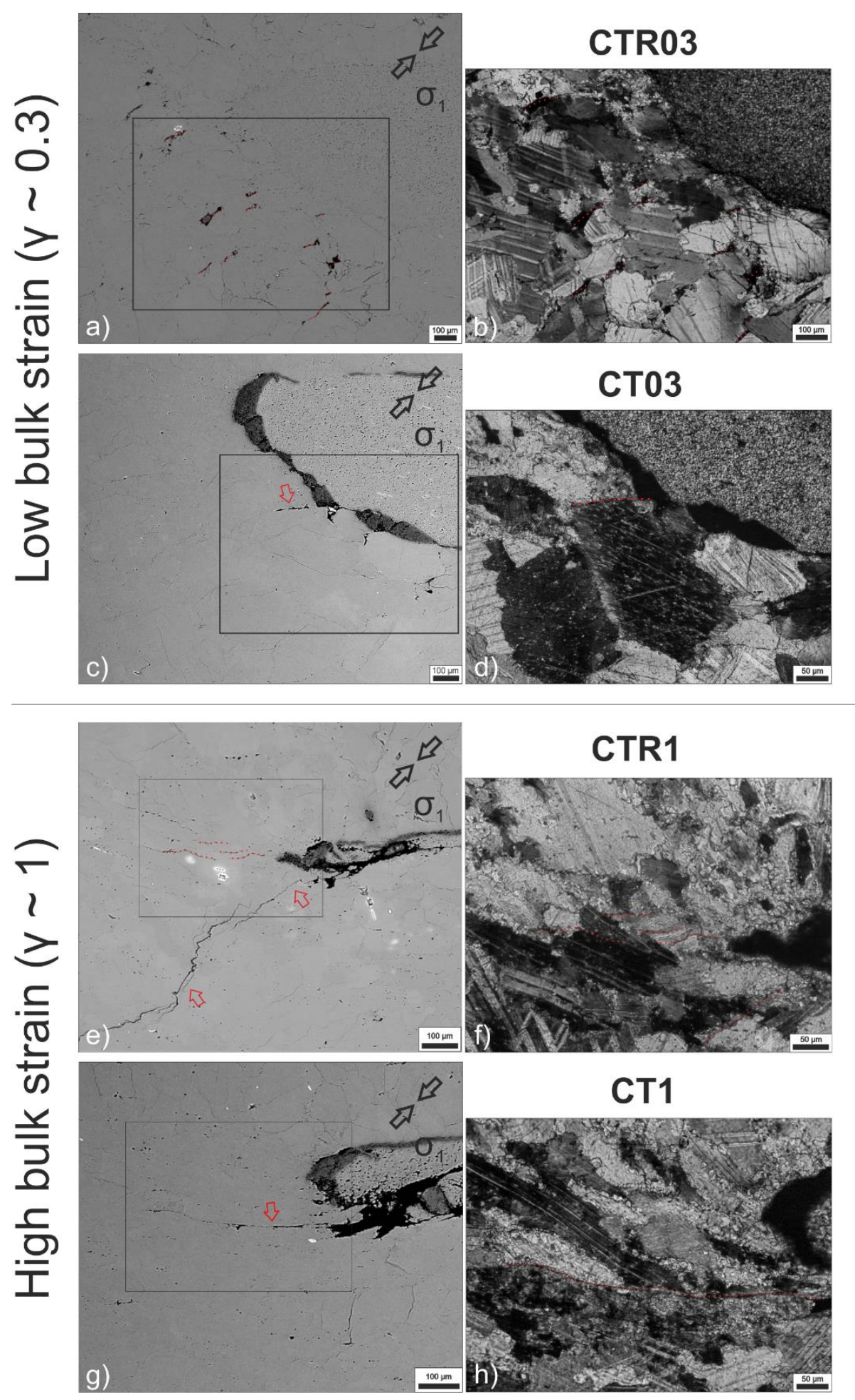

Fig. 8 a-h: SEM images and optical close-ups of brittle features in the deformed samples for low (a-d) and high (e-h) bulk strain. Applied loading conditions are specified in brackets together with the sample number. The 275 direction of maximum compressive stress, $\sigma_{1}$ is indicated in the upper right corner of the SEM images. The orientation of brittle cracks with respect to the direction of the principal stress is somewhat different at low strain between constant twist rate $(a-b)$ and constant torque $(c-d)$. Note voids that formed ahead of the inclusions (dotted segments in a). Dark seam at inclusion/matrix interface (c) is deformed ceramic cement. Note abundant pores decorating open and closed grain boundaries around the inclusion tip. With increasing bulk strain, similarly oriented fractures are present in both samples, while in the constant twist rate sample (e-f) a single fracture with 
similar orientation as at lower strain (a-b) is present. Cracks may have been enhanced by unloading at the end of the experimental run.

Many grain boundaries in the process zone surrounding the inclusion tip are decorated by strings of pores. It is conceivable that these indicate crack closure and healing during the tests. The displacement associated with the shear fracture is accommodated by the weakest phase (the limestone), as can be observed in the relative movement of the ceramic glue at the contact between the marble and the inclusion. At higher bulk strain (Fig. 8e-h), a long single shear fracture is observed in the constant torque sample (Fig. $8 \mathrm{~g}$-h). In constant twist rate conditions (Fig. 8e-f) a few small incipient intracrystalline cracks developed at the very tip of the soft inclusion. No substantial offset can be discerned along these small cracks. A large, extended fracture oriented consistently to the direction of $\sigma_{1}$ is seen in this sample, potentially enhanced during unloading given its extension, developing beyond the microstructurally defined process zone.

\subsection{Grain size and grain shape evolution}

The microstructures of the investigated samples vary strongly on the sample scale as a result of the strain partitioning between limestone inclusion and host Carrara marble, and within the marble matrix due to the local stress concentration at the interface between the two materials. To investigate the distribution of these heterogeneities within samples and between specimens deformed at different conditions we collected EBSD data and performed analysis of grain size distribution and characterized the grain shape evolution (for details on the methods applied, see section 3). Based on optical observations measuring some tens of recrystallized grains per thin section, average grain size of dynamically recrystallized grains was estimated to $20 \pm 4 \mu \mathrm{m}$.

\subsubsection{Grain size evolution}

305 Figures 9a (low bulk strain samples) and 9b (high bulk strain samples), respectively, show profiles of average grain size plotted against vertical distance from the inclusion (above and below; red rectangles in Fig. 9a and b indicate the approximate location of the inclusion). For details on the parameters used for the construction of profiles, see section 3. Significantly reduced average grain size down to about $60 \mu \mathrm{m}$, as a result of intense dynamic recrystallization, is clearly visible in the process zone of all samples. Up to a shear strain of 0.3 a clear symmetry in the average grain size evolution across the process zone is displayed (Fig. 9a). At high strains of about 1 the development of two distinct domains on opposite sides of the inclusion becomes more evident, with lower average grain size values in the lower sector of the samples (Fig. 9b, note the different slopes of the profiles on opposite sides of the inclusion). The applied loading conditions have no significant effect on 
grain size evolution, suggesting that the amount of recrystallized material associated with localized deformation is not substantially dependent on the imposed boundary conditions.

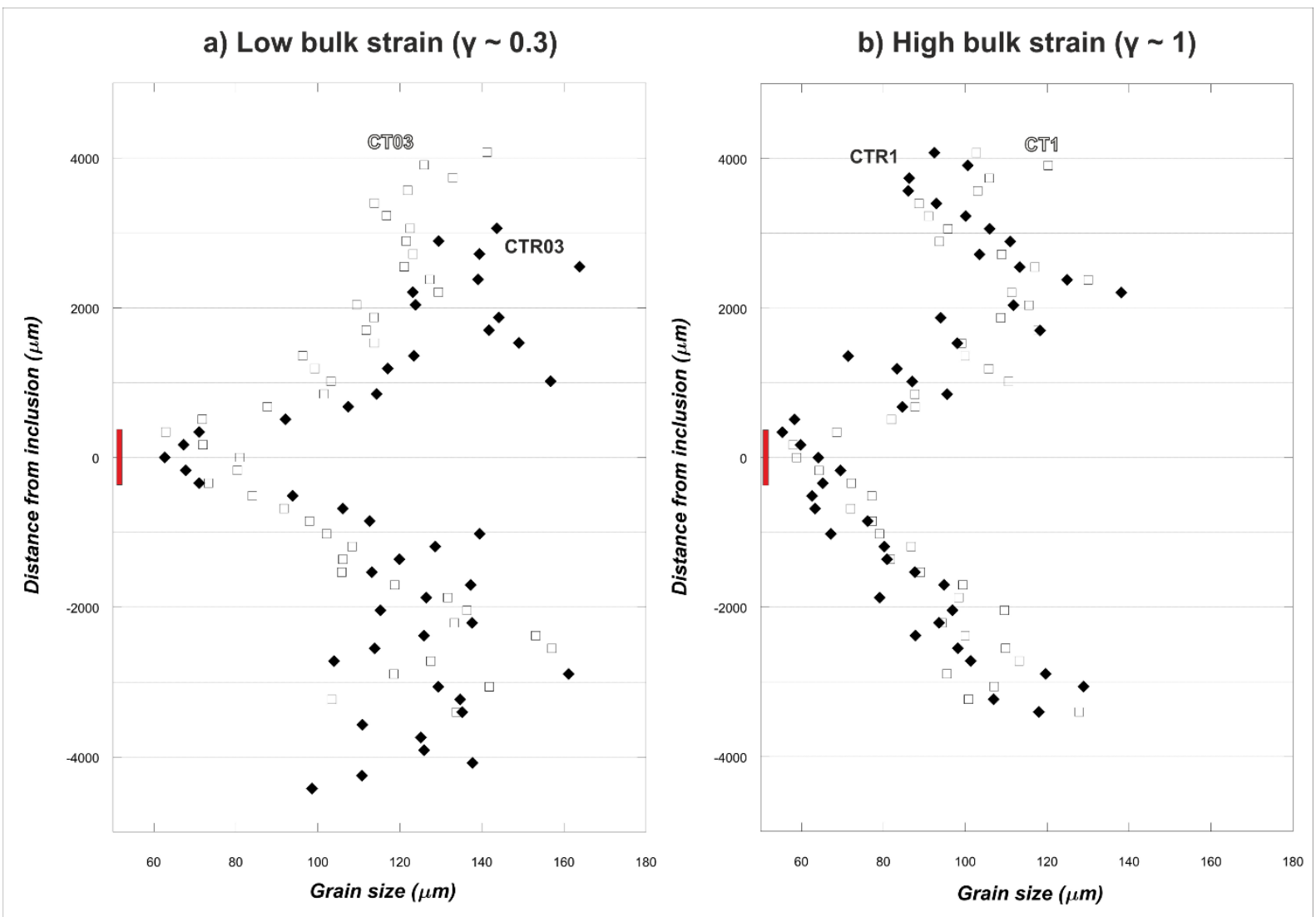

Fig. $9 a$ and $b$ : Evolution of average grain size across the thin section, above and below the process zone where deformation localizes in front of the limestone inclusion (the position of the inclusion is indicated in red). a) bulk strain $=0.3 ;$ b) bulk strain $=1$.

The finer step size EBSD maps (see section 3) were used to investigate three regions of the samples in more detail (here referred to as upper domain, process zone and lower domain; Fig. 3a-d). The grain size distributions for all three domains, for the cumulative area of the maps and for the undeformed starting material are shown in terms of area fraction vs equivalent diameter (Fig. 10; diameter of a circle of equivalent area to each grain). Solid, dashed and stippled lines indicate the median values for constant twist rate, constant torque and starting material samples, respectively (see Table 2 for a transcription of the values). For both low and high bulk shear strains the overall grain size distributions of constant torque and constant twist rate samples within the whole thin section area are largely overlapping with rather similar median values (Fig. 10a and e). In all samples, the average grain sizes are significantly reduced in the process zones compared to adjacent domains and the starting material. Reduction of average grain size outside the process zone is more pronounced at high strain (cf. median lines in Fig. 10h compared to Fig. 10d) as a consequence of the increased contribution of dynamically recrystallized grains. 


\begin{tabular}{|c|c|c|c|c|c|}
\hline \multirow{2}{*}{ Domain } & \multicolumn{2}{|c|}{ Low bulk shear strain samples } & \multicolumn{2}{|c|}{ High bulk shear strain samples } & \multirow{2}{*}{$\begin{array}{l}\text { Starting } \\
\text { material }\end{array}$} \\
\hline & CTR03 & CT03 & CTR1 & CT1 & \\
\hline $\begin{array}{l}\text { Whole } \\
\text { section }\end{array}$ & $158.52 \mu \mathrm{m}$ & $168.41 \mu \mathrm{m}$ & $134.52 \mu \mathrm{m}$ & $132.55 \mu \mathrm{m}$ & \multirow{4}{*}{$\begin{array}{c}214.17 \\
\mu \mathrm{m}\end{array}$} \\
\hline $\begin{array}{c}\text { Upper } \\
\text { domain }\end{array}$ & $183.06 \mu \mathrm{m}$ & $218.44 \mu \mathrm{m}$ & $180.12 \mu \mathrm{m}$ & $163.39 \mu \mathrm{m}$ & \\
\hline $\begin{array}{c}\text { Process } \\
\text { zone }\end{array}$ & $114.77 \mu \mathrm{m}$ & $136.28 \mu \mathrm{m}$ & $115.8 \mu \mathrm{m}$ & $102.14 \mu \mathrm{m}$ & \\
\hline $\begin{array}{c}\text { Lower } \\
\text { domain }\end{array}$ & $169.77 \mu \mathrm{m}$ & $154.44 \mu \mathrm{m}$ & $116.18 \mu \mathrm{m}$ & $137.27 \mu \mathrm{m}$ & \\
\hline
\end{tabular}

Table 2: Median values (equivalent diameter, in $\mu \mathrm{m}$ ) for the area fraction grain size distribution presented in Figure 10. 


\section{Low bulk strain}
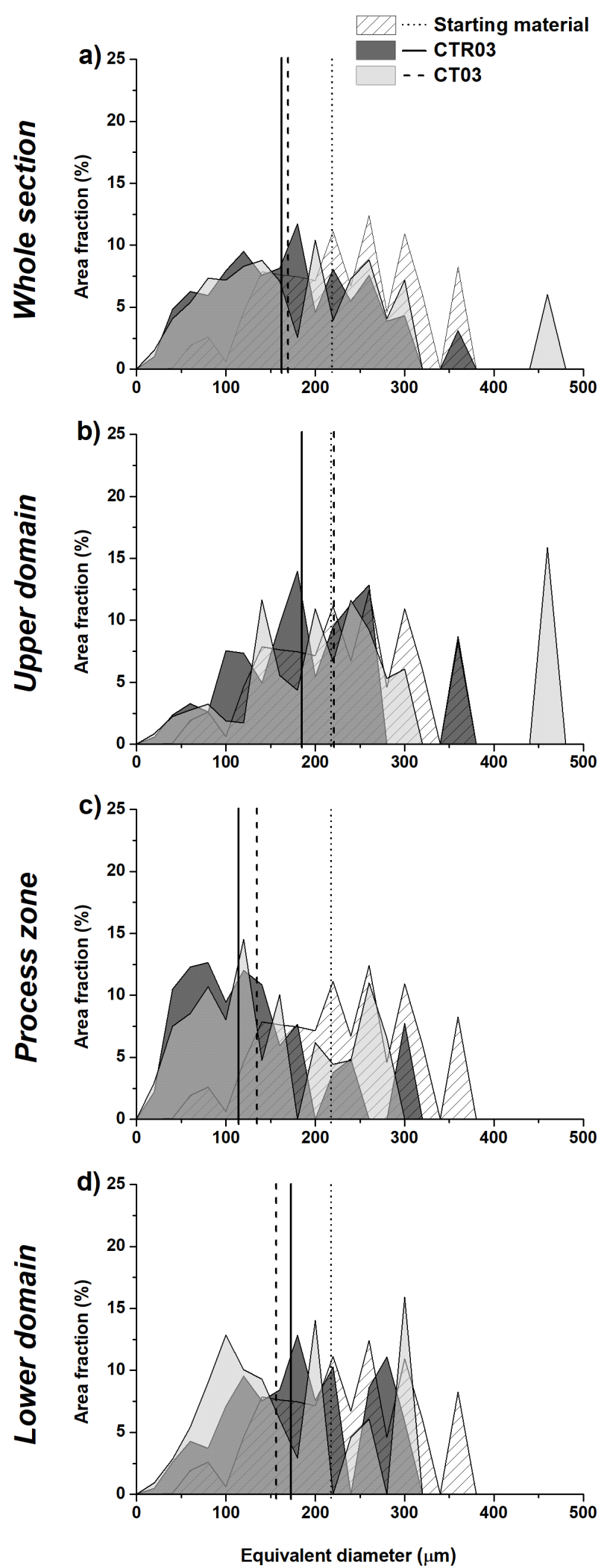

High bulk strain
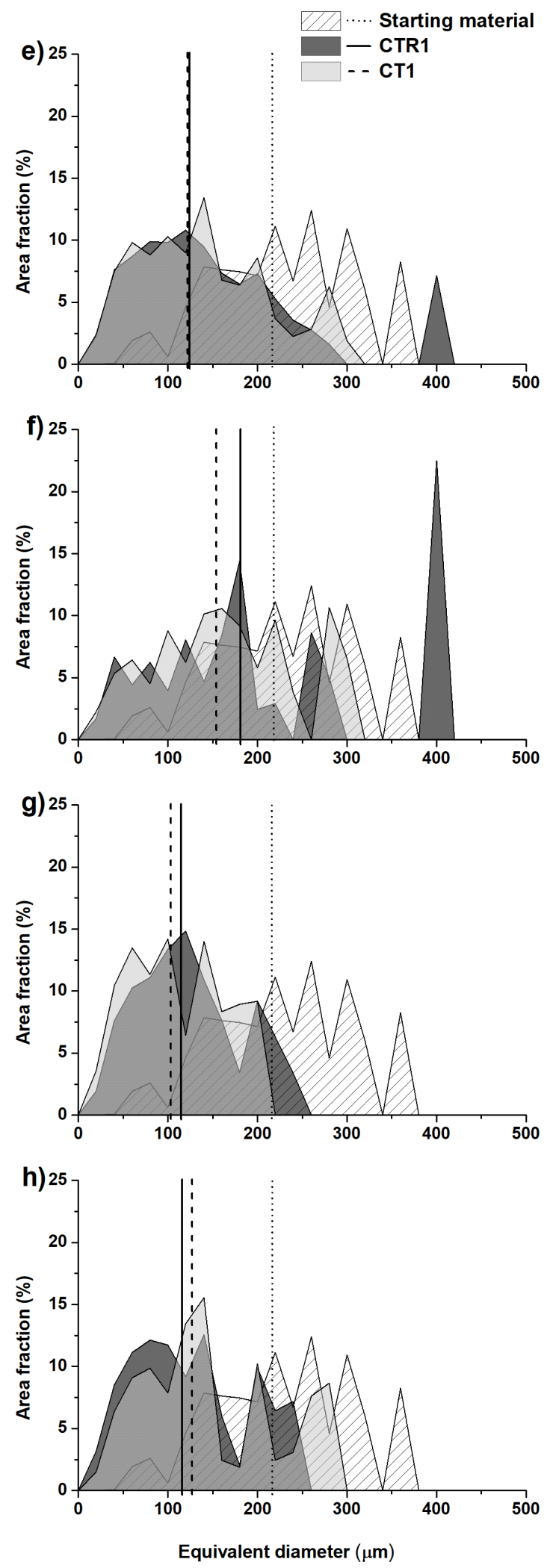

Fig. 10 a-h: Grain size distribution expressed as normalized area fraction within domains described in text (upper, lower domains and process zone) and for the whole thin section for the two populations of samples (low bulk strain in a-d, high bulk strain in e-h) compared to the starting material. Solid, stippled and dotted lines indicate the median value of grain size distribution for constant twist rate, constant torque samples and undeformed material, 
respectively. The median grain size in the process zone of all deformed samples is significantly smaller than in adjacent domains and compared to the starting material.

For low strain samples (Fig. 10b-d) the strongest grain size reduction occurs within the process zone (Fig. 10c), where the applied loading conditions appear to play no role in the resulting distribution. Upper and lower domains (Fig. 10b and d) display some subtle differences in evolution between constant twist rate (CTR03) and constant torque (CT03) samples. For constant twist rate samples, grain size distributions are similar above and below the process zone. Samples deformed at constant torque show a generally lower average grain sizes in the domain below the process zone (Fig. 10d). In general, however, grain size evolutions are very similar in samples deformed at different loading conditions. At high strain, the asymmetry in grain size evolution between the upper and lower domain is preserved (also seen in Fig. 9), but the difference between loading conditions is reduced (Fig. 10 and h). Note, however, that the overall grain size evolution (Fig. 9) and distribution (Fig. 10a and e) ultimately appear not to be influenced by the imposed boundary conditions.

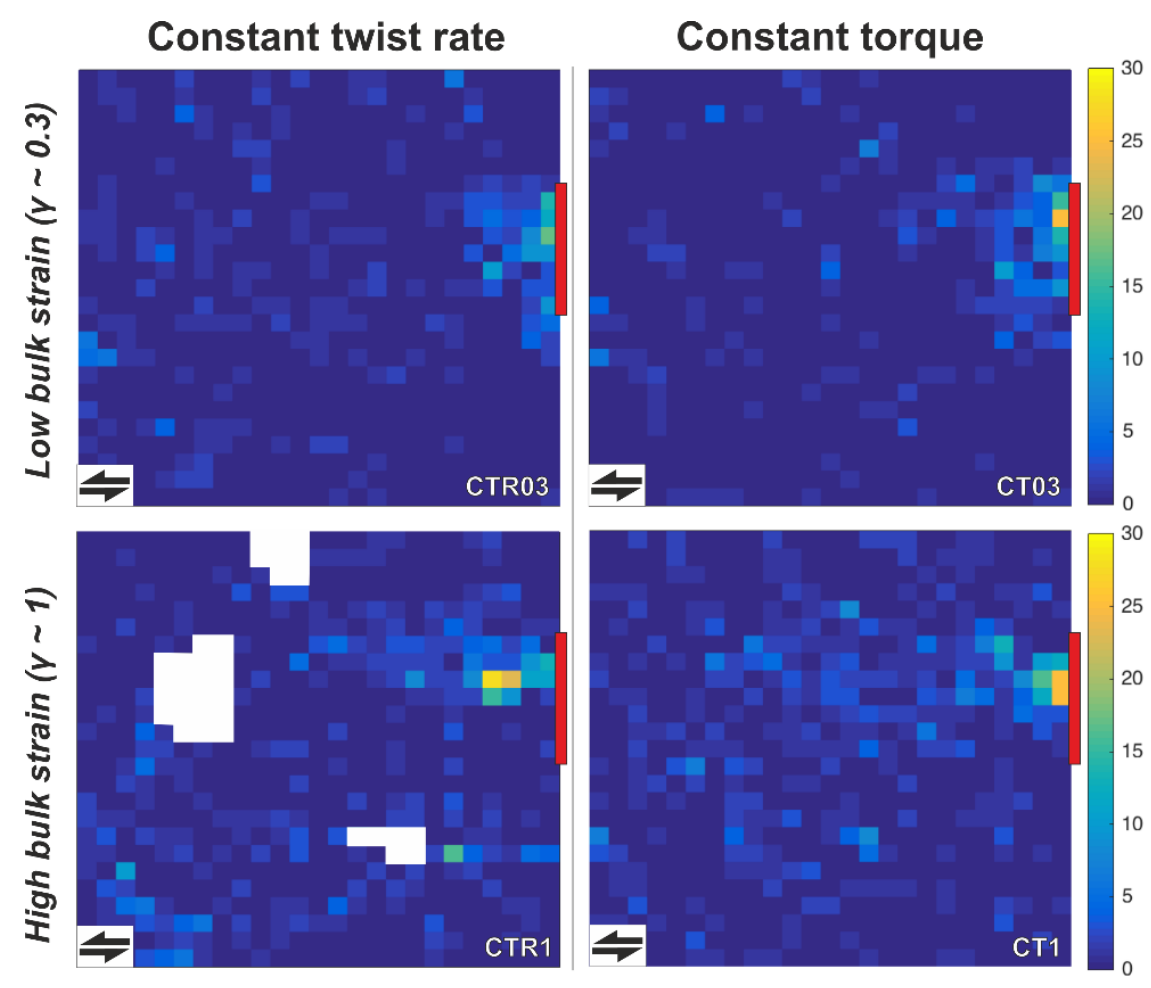

355 Fig. 11: Bivariate histograms showing the spatial distribution of small recrystallized grains (eq. diameter $<20 \mu \mathrm{m})$ for constant twist rate (left) and constant torque (right) samples. A 25x25 grid was defined over the region of interest where the calculation is carried out (black rectangles, Fig. 3a-d); the scale indicates the number of measurements within each unit of the grid. A red bar indicates the approximate position of the inclusion prior to deformation. The white polygons in sample CTR 1 correspond to patches of misindexed data (where the thin section was damaged) that were computed as artificial small grains by the mtex toolbox.

The spatial distribution of dynamically recrystallized grains across the combined three domains (stippled black rectangle in Figure 3a-d) using $3.5 \mu \mathrm{m}$ step size maps is plotted in 
Fig. 11. Bivariate histograms are constructed by defining a 25×25 grid colour coded based on how many recrystallized grains (equivalent diameter $<20 \mu \mathrm{m}$ ) are present within each grid square. The frequency of recrystallized grains is largest ahead of the inclusion and increases with increasing bulk strain. No major differences can be observed between the different loading conditions. This is in good accordance with the observation that the area fraction of grains with equivalent diameter smaller than $20 \mu \mathrm{m}$ is similar in samples deformed at both imposed boundary conditions (Fig. 10a and e).

\subsubsection{Grain shape evolution}

We determined the average grain shape within the aforementioned domains to analyze the degree of plastic deformation of the matrix material (see section 3 for details). In Figure 12aI, normalized circularity and inverse aspect ratio data are plotted within the three area domains for the two considered bulk strains (Fig. 12a-f, $\gamma \sim 0.3$ and Fig. 12g-I $\gamma \sim 1.0$; the data is normalized to the total number of grains).
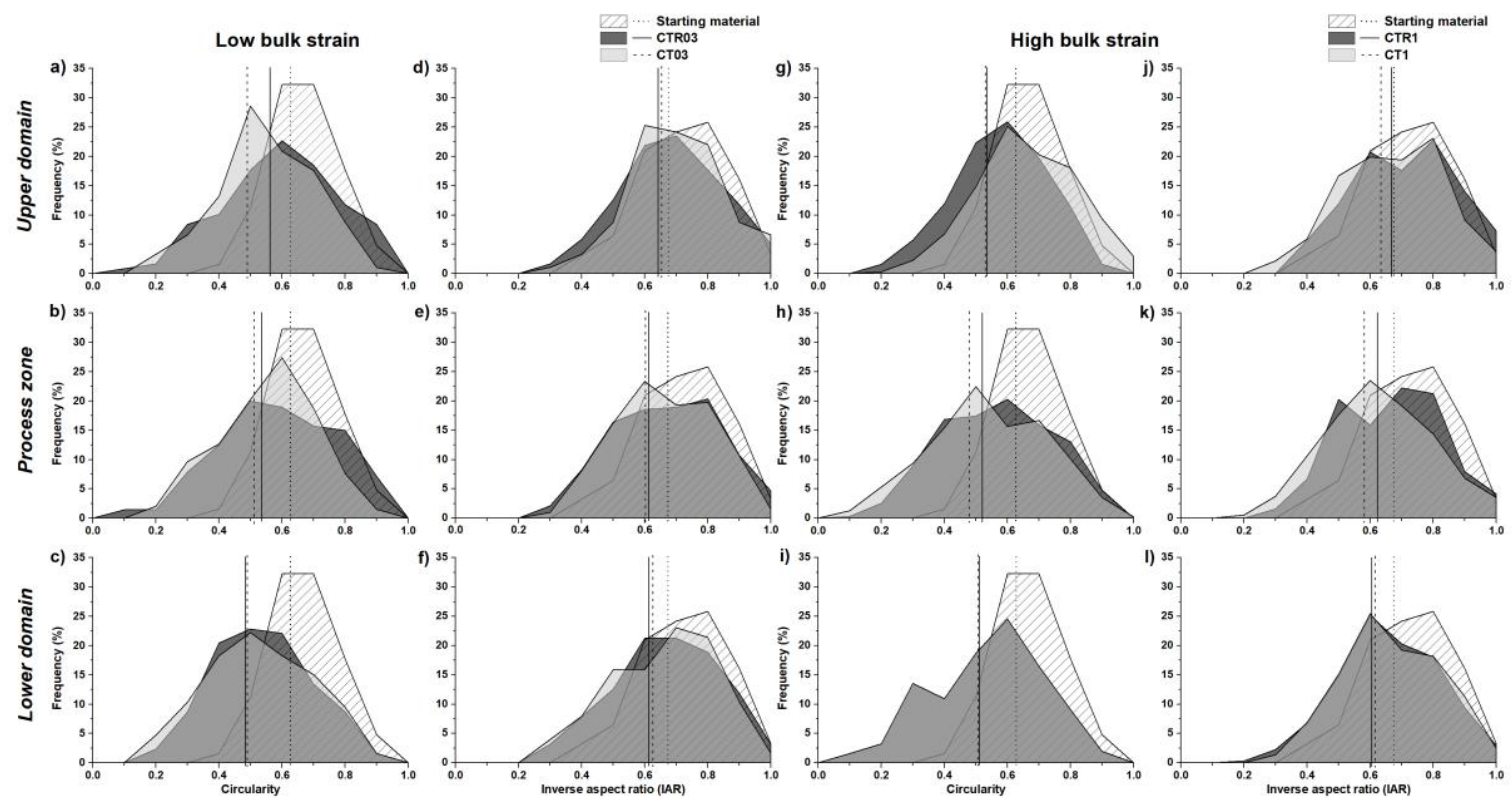

Fig. 12 a-l: Frequency histograms for the two shape descriptors considered (circularity in a-c and g-i and inverse aspect ratio in $d-f$ and $j-I$ ) within the three described domains (upper, lower and process zone) for all samples (low bulk strain in a-f and high bulk strain in $\mathrm{g}-\mathrm{I}$ ) with comparison to starting material distributions. Vertical lines indicate the median value of each distribution. For detailed description see text.

The shape distribution of the starting material (hatched curves) is given for comparison. Vertical lines indicate the median values of each distribution.

The histograms in Figs. 12a-c and 12g-i show the distribution of circularity data, i.e. a measure of the roughness of grain boundaries, at low and high bulk strain, respectively. A comparison of the median values shows that the imposed boundary conditions do not produce a very significant difference in the distribution of circularities within any of the 
domains considered. Compared to the starting material distribution, both constant twist rate (CTR03, CTR1) and constant torque (CT03, CT1) samples show an overall increase in surface roughness (decrease in circularity values) across the entire thin section. The similarities between different boundary conditions are also found for the inverse aspect ratio data, especially at low strains (Fig. 12d-f). Within the general trend of increased ellipticity (decreased inverse aspect ratio) with respect to the starting material distribution, small differences are present in the process zone of high strain samples (Fig. 12k).

\subsection{Local stress concentration at the tip of the inclusions}

The observations carried out on macrostructural and microstructural data indicate that strain is locally concentrated within the Carrara marble in front of the weak Solnhofen inclusion. This suggests that the distribution of stress within the samples is also strongly heterogeneous. Stress appears to be locally enhanced in regions around the inclusion tips that experience the highest amounts of dynamic recrystallization and intracrystalline deformation. Several paleopiezometer techniques may be used to estimate local stresses (e.g. recrystallized grain size, dislocation density, twin density), but they all rest on the assumption that the considered microstructures are in equilibrium with the thermodynamic conditions. On the scale of the entire sample we observe a transient evolution of both strength and microstructure as the shear zone propagates into the Carrara matrix. Although on a local scale (process zone) we may have reached local equilibrium of stress and microstructure this is not the case for the entire samples considered here. The results presented in the following in terms of recrystallized grain size and dislocation density piezometry are therefore expected to represent lower and upper bounds, respectively, to the true stress values locally experienced by the samples. Recrystallized grains may be larger than the equilibrium size at the given stress conditions (lower bound), while the density of free dislocations might not be fully re-equilibrated to the local stress (upper bound).

Calibration of the recrystallized grain size piezometer for Carrara marble has been carried out at different experimental conditions by several authors (Schmid et al., 1980; Rutter, 1995; De Bresser, 1996; Barnhoorn et al., 2004). In this study, we applied the piezometer from Barnhoorn et al., 2004 calibrated on high strain torsion experiments performed between 500 and $700^{\circ} \mathrm{C}$ and from Rutter, 1995, who used triaxial compressive and extensional configurations at temperatures between 500 and $1000{ }^{\circ} \mathrm{C}$. The general relationship between stress and recrystallized grain size is given by:

$$
\sigma=C \times d^{m}
$$


where $\sigma$ is the equivalent stress, $d$ is the recrystallized grain size, and $C$ and $m$ are two constants. Note that the conversion from shear to equivalent stress is defined as follows

(Paterson and Olgaard, 2000):

$$
\tau=\frac{1}{\sqrt{3}} \sigma
$$

The values of the two constants are 573.03 and -0.82 , respectively, calibrated by Barnhoorn et al., 2004 and 812.83 and -0.88 using Rutter's 1995 calibration. Note that both piezometers are based on the assumption that subgrain rotation is the predominant recrystallization mechanism, as is expected from our microstructural observations (see section 4.3).

For the determination of recrystallized grain sizes within a lateral distance of about $500 \mu \mathrm{m}$ from the inclusion, between 50 and 100 grains were digitized in each of the samples, and the average of their equivalent diameters was calculated. Results show stress concentration with respect to the applied bulk stress of 2.2-3.1 and 2.9-4.2 using the Barnhoorn and Rutter calibration, respectively (Tab. 3). Within error in grain size determinations, calculated stress values are independent of bulk finite strain and loading conditions.

\begin{tabular}{|l|c|c|c|c|c|c|c|}
\hline $\begin{array}{c}\text { Sample } \\
\text { name }\end{array}$ & $\begin{array}{c}\text { Loading } \\
\text { conditions }\end{array}$ & $\begin{array}{c}\text { Total } \\
\text { imposed } \\
\text { bulk } \\
\text { strain }(\mathrm{y})\end{array}$ & $\begin{array}{c}\text { Recrystallized } \\
\text { grain size }(\mu \mathrm{m})\end{array}$ & $\begin{array}{c}\text { Calculated } \\
\sigma(\mathrm{MPa})- \\
\text { Barnhoorn } \\
\text { et al., 2004 }\end{array}$ & $\begin{array}{c}\text { Stress } \\
\text { concentration }\end{array}$ & $\begin{array}{c}\text { Calculated } \\
\sigma(\mathrm{MPa})- \\
\text { Rutter, } \\
1995\end{array}$ & $\begin{array}{c}\text { Stress } \\
\text { concentration }\end{array}$ \\
\hline CTR03 & CTR & 0.29 & $10 \pm 4$ & $77 \pm 30$ & 2.2 & $100 \pm 40$ & 2.9 \\
\hline CT03 & CT & 0.29 & $9 \pm 3$ & $87 \pm 20$ & 2.5 & $115 \pm 30$ & 3.4 \\
\hline CTR1 & CTR & 0.99 & $9 \pm 3$ & $85 \pm 20$ & 2.5 & $113 \pm 30$ & 3.3 \\
\hline CT1 & CT & 0.94 & $8 \pm 3$ & $101 \pm 35$ & 3.1 & $135 \pm 40$ & 4.2 \\
\hline
\end{tabular}

Table 3: Estimated recrystallized grain size and corresponding calculated equivalent stresses. Stress concentration factor $=$ local $/$ bulk stress ratio.

Dislocation densities at increasing distance from the tip of the weak Solnhofen inclusion were estimated using transmission electron microscopy (TEM) of sample CTR03 (low bulk strain constant twist rate). Six foils of $0.15 \mu \mathrm{m}$ thickness were prepared from areas within relict deformed grains at incremental distances of $\sim 500 \mu \mathrm{m}$ (Fig. 13a). The foils were examined in STEM mode (scanning transmission electron microscope). Detailed images of each foil were acquired at 5 different tilt angles to highlight the number of visible dislocations. Subsequently, detailed images were stitched together and, by means of a user defined grid, spatial densities of free dislocations (number of dislocations per unit area, i.e. the number of free dislocations that would intersect the linear traverses of the grid) were manually calculated for all the tilt angles considered. Following De Bresser, 1996, the density is defined as: 


$$
\rho=\frac{2 N}{\lambda t}
$$

where $N$ is the number of intersections, $\lambda$ the length of the transect line and $t$ the (constant) thickness of the TEM foil.

450 The piezometer was calibrated by De Bresser, 1996 on both single crystals and polycrystalline calcite deformed between $550-800^{\circ} \mathrm{C}$, yielding:

$$
\sigma=10^{-6.21} \times \rho^{-0.62}
$$

where $\sigma$ is the equivalent stress in MPa and $\rho$ is the dislocation density in $\mathrm{m}^{-2}$.

Resulting stresses show significant error bars (as a consequence of the uncertainty in the measured dislocation densities), but decrease non-linearly with distance (Fig. 13b). With respect to the applied bulk equivalent stress of $34.8 \mathrm{MPa}$, the resulting stress concentration at the tip of the inclusion is approximately a factor 2 , in accordance with the results from the recrystallized grain size piezometry.

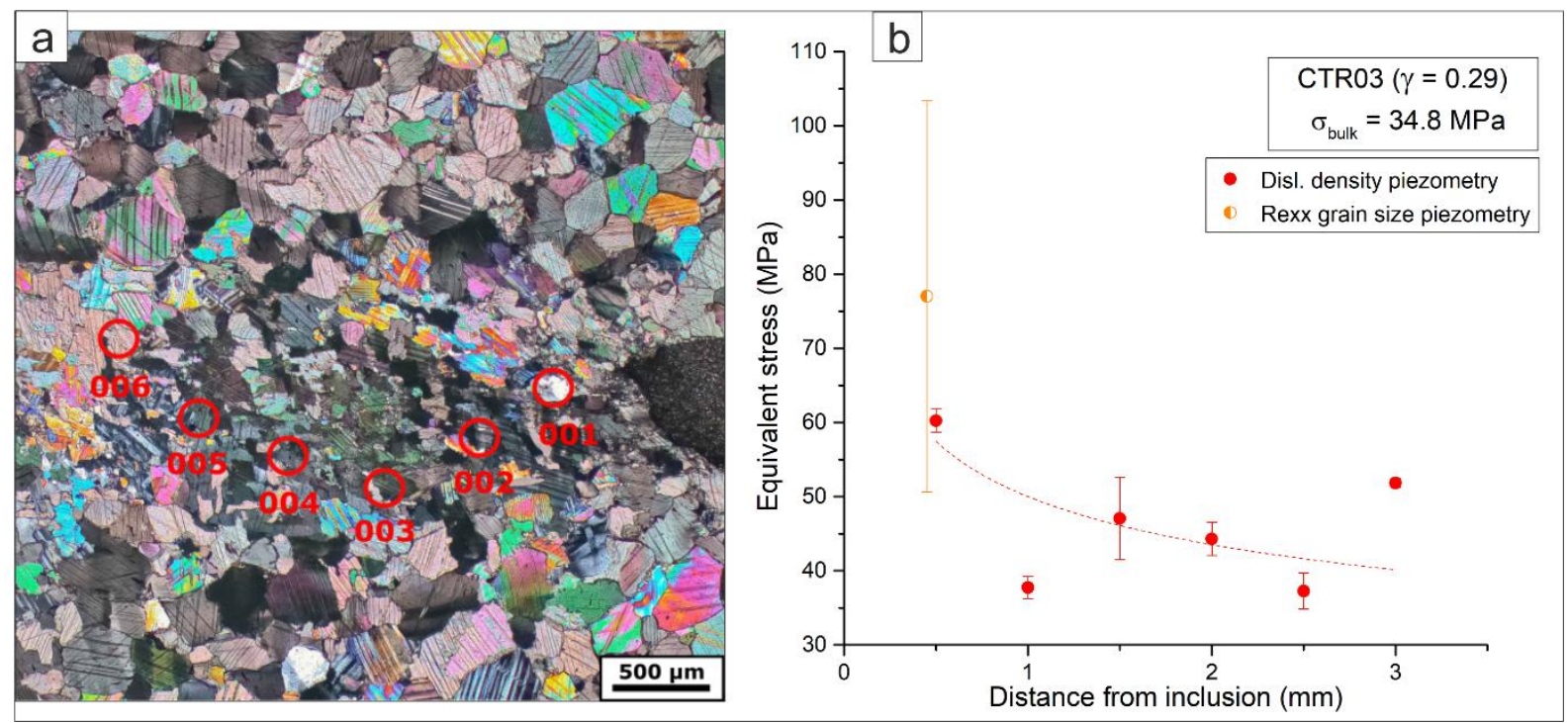

460 Fig. 13 a and b: a) Micrograph of sample CTR03 with approximate locations of FIB foils for TEM analysis, b) local stress with distance from the inclusion tip as calculated using dislocation density (red) and recrystallized grain size (orange) piezometry.

\subsection{Crystallographic preferred orientation}

For the calculation of pole figures, maps produced with a 10 microns step size were used. A rectangular area of the thin sections covering the process zone was analyzed for all samples. Irrespective of applied loading conditions, a strong CPO developed in the deformed samples with increasing strain. Samples deformed at constant torque and constant twist rate show comparable textural evolution (Fig. 14b-e) and pole figures that differ significantly from the starting material (Fig. 14a). 
In CTR03 (low strain constant twist rate sample, Fig. 14b), the [0001] axes are distributed along a rather complete girdle normal to the shear plane and with two maxima at a high angle to the pole of the shear plane. For this sample, an incipient alignment of the poles of $\{10-14\}$ with the pole of the shear plane is observed, while the poles of $\{11-20\}$ appear to be quite scattered, with a component parallel to the shear direction.

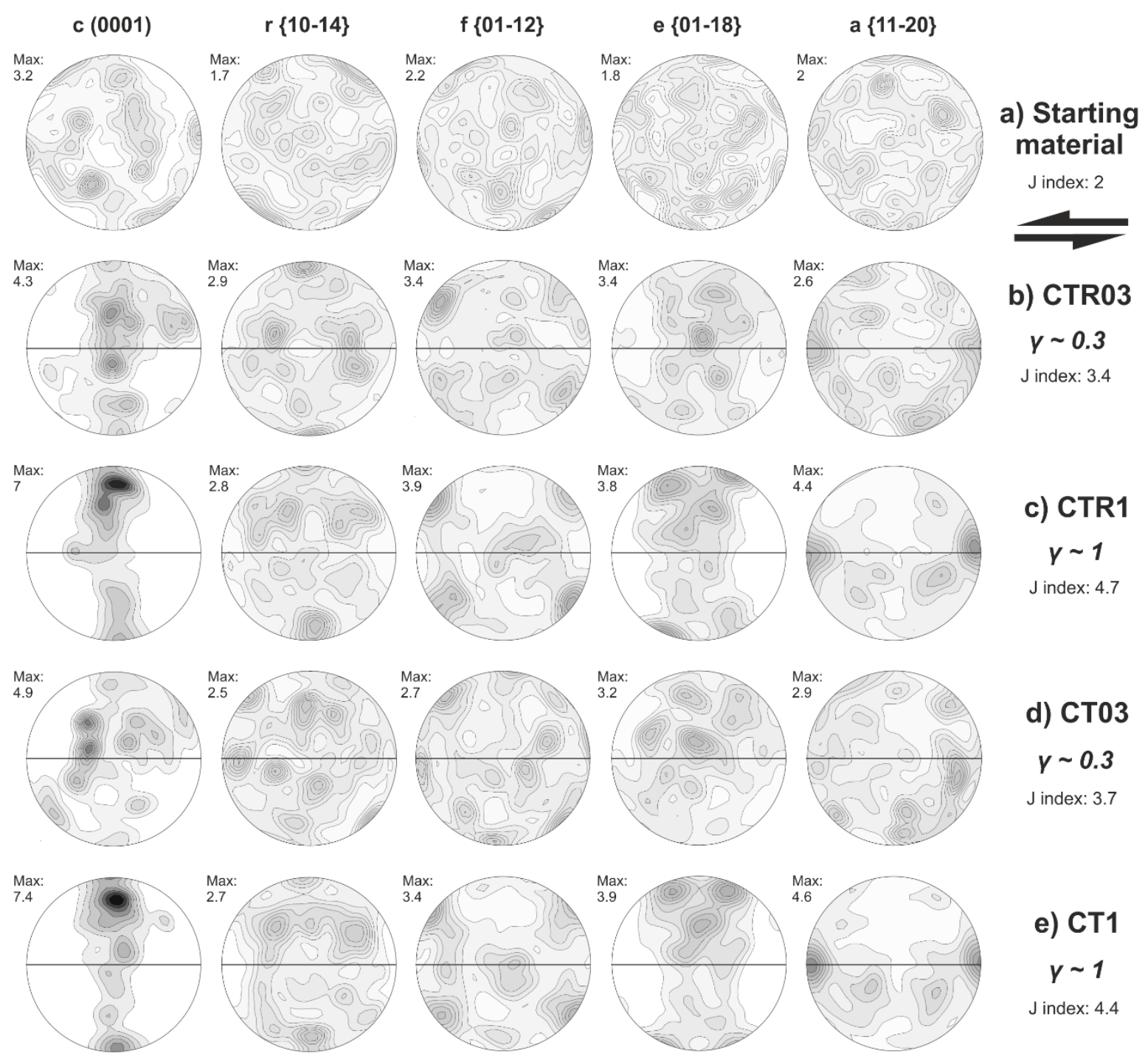

475 Fig. 14 a-e: Crystallographic preferred orientation of calcite in Carrara marble a) from the undeformed sample or b-e) within the process zone of the experimental samples (as defined in fig. 3a-d), for the poles of basal (c (0001)), rhomb ( $\mathrm{r}\{10-14\}, \mathrm{f}\{01-12\}),(\mathrm{e}\{01-18\})$ and prismatic $(\mathrm{a}\{11-20\})$ planes. Orientation of shear plane is indicated by arrows at the top right of the figure.

The $\{01-12\}$ poles are distributed across two clear maxima at an angle of $\sim 45^{\circ}$ to the shear direction. With increasing strain (Fig. 14c), the girdle of [0001] poles becomes more continuous and it cross-cuts the shear plane, also developing a strong maximum around $20^{\circ}$ to the shear plane pole. While the $\{10-14\}$ poles undergo some dispersion, poles of $\{11-20\}$ strengthen the parallelism to the shear direction. Similarly, $\{01-12\}$ poles preserve the two described maxima and develop two more, also at $\sim 45^{\circ}$ to the shear direction. Poles of $\{01-$ 
$18\}$ form small girdles perpendicular to the shear zone, with a maximum concentration at an angle $\left(\sim 15^{\circ}\right)$ to the shear plane pole.

In constant torque samples (Fig. 14d-e), CT03 presents a weak texture similar to the low strain, constant twist rate experiment. Poles of [0001] display a weak girdle with a maximum at about $30^{\circ}$ from the center of the pole figure within the shear reference plane and two incipient weak maxima oblique $\left(\sim 45^{\circ}\right)$ to the shear plane and opposite the shear direction are also visible. The poles to $\{10-14\}$ and $\{11-20\}$ planes are rather dispersed, although these latter display maxima normal and at $\sim 45^{\circ}$ to the shear plane. Poles of $\{01-12\}$ are again arranged in four symmetrical maxima at $\sim 45^{\circ}$ to shear direction, with the addition of further maxima normal and sub-parallel to the shear plane. With increasing strain (Fig. 14e), the CPO strengthens substantially, similar to the sample deformed at constant twist rate. Poles of [0001] are now arranged in one single girdle normal to the shear plane, with one dominant maximum at $\sim 20^{\circ}$ to the poles of the shear plane. The $\{10-14\}$ poles show an alignment parallel to the shear plane, while the poles of $\{11-20\}$ seem to follow the shear direction. Poles of $\{01-12\}$ are arranged in four symmetrical maxima as described for the constant twist rate sample. A strong preferred orientation is observed for $\{01-18\}$ poles as well, forming girdles around the normal to the shear plane.

\section{Discussion}

\subsection{Weakening mechanisms}

Plastic strain localization requires the development of an instability in the system undergoing deformation (Poirier, 1980; Hobbs et al., 1990). It is generally assumed that potentially coexisting weakening mechanisms (recrystallization-induced grain size reduction, CPO formation, reaction softening, shear heating) may lead to local strength perturbations and ultimately to strain localization (for a review, see Fossen and Cavalcante, 2017).

At the given experimental conditions, Carrara marble is expected to deform in the dislocation

510 creep regime (e.g. Schmid et al., 1987; Pieri et al., 2001a, b; Rybacki et al., 2014). This assumption is confirmed by the observed presence of a strong crystallographic preferred orientation even at early increments of bulk shear strain (Fig. 14). Moreover, the increased mean aspect ratio of relict grains with respect to the undeformed starting material (Fig. 15ab) associated with the development of a SPO within the process zone of the investigated samples (Fig. 15c-d) are indicative of intracrystalline deformation. 

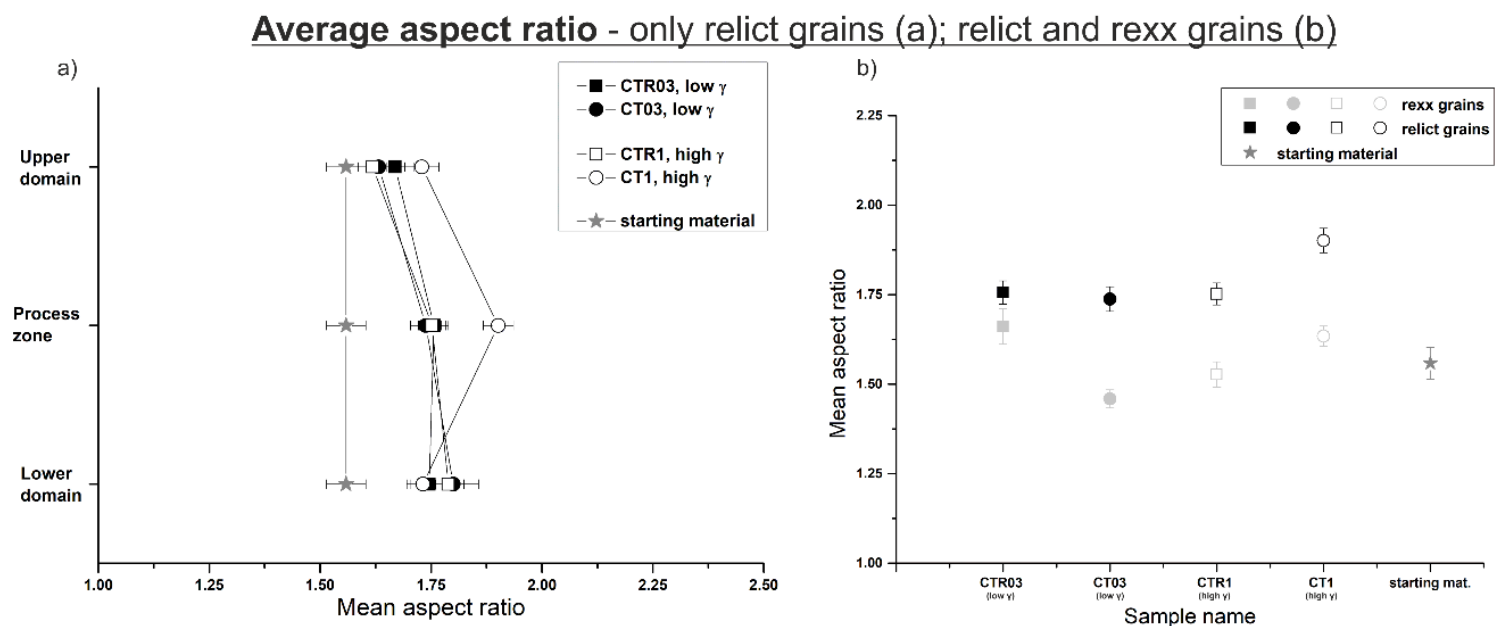

Shape preferred orientation - only relict grains

c) Low bulk shear strain $(y \sim 0.3)$ Constant twist rate (CTR03)
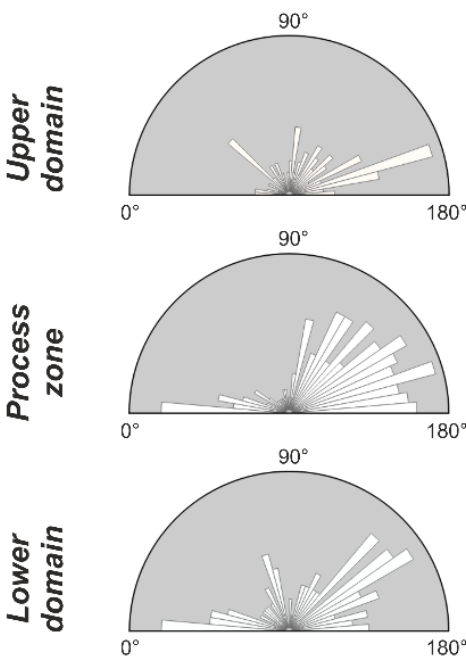

Constant torque (СТ03)
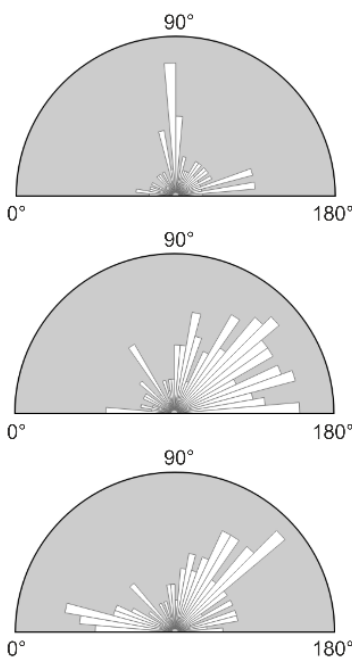

d) High bulk shear strain $(y \sim 1)$ Constant twist rate (CTR1) Constant torque (CT1)
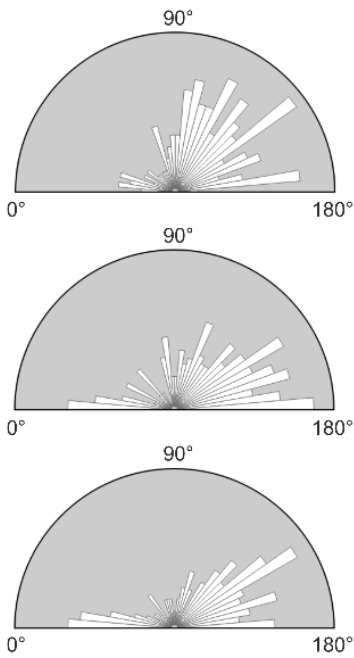
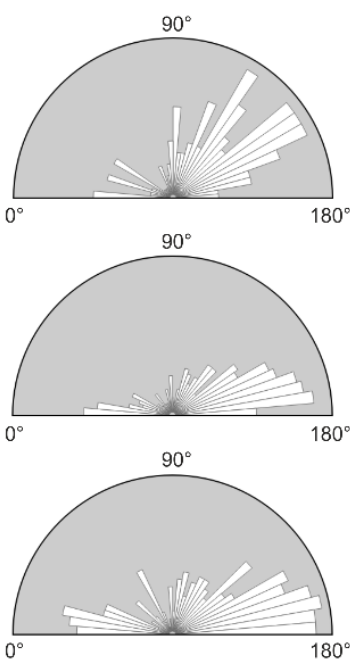

Fig. 15 a-d: (a) Analysis of mean aspect ratio of relict grains (equivalent diameter $>20 \mu \mathrm{m}$ ) across the vertical profiles defined in Fig. 3a-d; (b) comparison of mean aspect ratios of relict (eq diam. $>20 \mu \mathrm{m}$ ) and recrystallized (eq. diam < $20 \mu \mathrm{m}$ ) grains within the process zone of the samples; (c, d) shape preferred orientation of relict grains (equivalent diameter $>20 \mu \mathrm{m}$ ) across the vertical profiles defined in Fig. 3a-d.

Intense, strain dependent grain size reduction by dynamic recrystallization is observed to develop dominantly in the process zone (Fig. 11), induced by the concentration of stresses and shear strain around the inclusion tip (Fig. 13). Some contribution of grain size sensitive diffusion creep is expected to be active in fine-grained regions in Carrara marble, as shown for the same experimental conditions and for recrystallized grain sizes in the order of 10-15 $\mu \mathrm{m}$ (ref. Fig. 13 in Rybacki et al., 2014). As discussed by the latter authors, the measured stress concentration at the tip of the inclusion may induce switching into the dislocation creep regime, suggesting that the weakening-controlling deformation mechanism in Carrara marble at the examined experimental conditions is grain size insensitive. This is supported by our observations indicating formation of cracks at the inclusion tip. 
The textural data (Fig. 14) allows identifying possible slip systems activated in the process zone of the samples, based on the classification of slip systems operating in calcite deformed at high temperature (e.g. De Bresser and Spiers, 1993). A general trend of switching main slip systems with increasing strain is observed in both constant twist rate and constant torque samples; while basal slip (notice the strong alignment of c-poles in Fig. 14c, e) is prevalent in both the high bulk strain samples, together with some remnants of slip along the rhomb $r$ plane in the a-direction $\{10-14\}<20-21>$, the low strain samples show a less strongly developed texture in which slip along the rhomb $r\{10-14\}$ and $f\{01-12\}$ planes in the $a<20-21>$ direction prevails (Fig. 14b, d). Strengths of the texture within the process zone, as quantified by the calculated j-index (Bunge, 1982), are similar for constant twist rate and constant torque samples at similar bulk strains. The presented pole figures are in good agreement with observations on calcite at similar conditions in previous studies (Schmid et al., 1987; Pieri et al., 2001a, b; Barnhoorn et al., 2004; Rybacki et al., 2014). The activity of similar slip systems and the analogous degree of textural development as a function of finite strain in our samples suggests that the deformation mechanisms active in the process zone are independent of applied loading conditions.

All deformed samples show cracks at the inclusion tips (Fig.8a-h). Cracks mostly follow grain boundaries and some open fractures are oriented parallel to the maximum compressive stress. Although some microcracks may have been induced by cooling and unloading, voids, low aspect ratio cracks and healed cracks clearly formed during the tests. Locally, where stresses are concentrated, brittle deformation assists in reducing grain size as described in natural examples of crustal scale shear zone networks (Fusseis et al., 2006; Fusseis and Handy, 2008). The microstructural observations show that brittle fracturing even occurs in combination with plastic deformation of calcite (Fig. 8). As the process zone propagates into the Carrara marble matrix, cracking is overprinted by high-temperature creep of the finegrained recrystallized matrix assisted by crack healing. It is conceivable that some of the cracking is also obliterated during unloading and slow cooling of the samples at the end of the experimental runs.

In CTR samples (Fig. 8a-b and e-f), microcracks and voids display a somewhat different distribution and orientation with respect to constant torque samples. At low strain, a set of small (50-100 $\mu \mathrm{m})$ cracks often oriented parallel to the direction of $\sigma_{1}$ is found (Fig. 8a-b). These are mostly open tensile cracks and in some cases associated with small, dynamically recrystallized material. At higher bulk shear strains (Fig. 8e-f), together with a long, interconnected fracture parallel to $\sigma_{1}$, some intracrystalline microcracks occur in parallel to the maximum shear direction. In both constant torque experiments (Fig. 8c- $d$ and g-h), a single fracture forms in plane with the shear propagation direction from the tip of the inclusion, consistent with the far field direction of maximum shear stress. It is, in all cases, 
difficult to assess with certainty whether any displacement is occurring along these fractures, as the presence of fine recrystallized material related to the ongoing plastic deformation overprints any possible passive marker in the microstructure. The preservation of such a fracture in both low and high bulk strain sample suggests its formation in the early stages of deformation and its further exploitation with increasing strain. Brittle deformation is, in all cases investigated, likely confined to small domains (where local stresses and strain rates are highest) and small intervals of strain, associated with pervasive high-temperature creep of calcite.

\subsection{Stress distribution and deformation transients}

The heterogeneous stress distribution produced in the matrix due to the presence of an inclusion is clearly expressed in the resulting microstructures. The stress enhancement in the marble matrix in the process zone in front of the inclusion tip is substantial and has been quantified to a factor of 2-3 with respect to the applied bulk stress (Tab. 3, Fig. 13), although it should be borne in mind that the paleopiezometers applied here were calibrated for steady state conditions not achieved in our tests (Rutter, 1995; De Bresser, 1996; Barnhoorn et al., 2004). Note that the amount of stress concentration surrounding a material heterogeneity depends on the effective viscosity contrast between inclusion and matrix and on coupling of the two materials (Kenkmann and Dresen, 1998). At given thermodynamic conditions of our tests, the initial viscosity contrast between Carrara marble and Solnhofen limestone is expected to be a factor $\sim 10$ (Rybacki et al., 2014). As suggested by the local shear strain, stress and grain size distributions found in the process zone, an exponential decay is observed with distance from the inclusion towards the matrix.

The time-dependent strain localisation pattern can be additionally investigated using numerical forward models (Döhmann et al., subm. to Journ. Geophys. Res., and Fig. 16). 

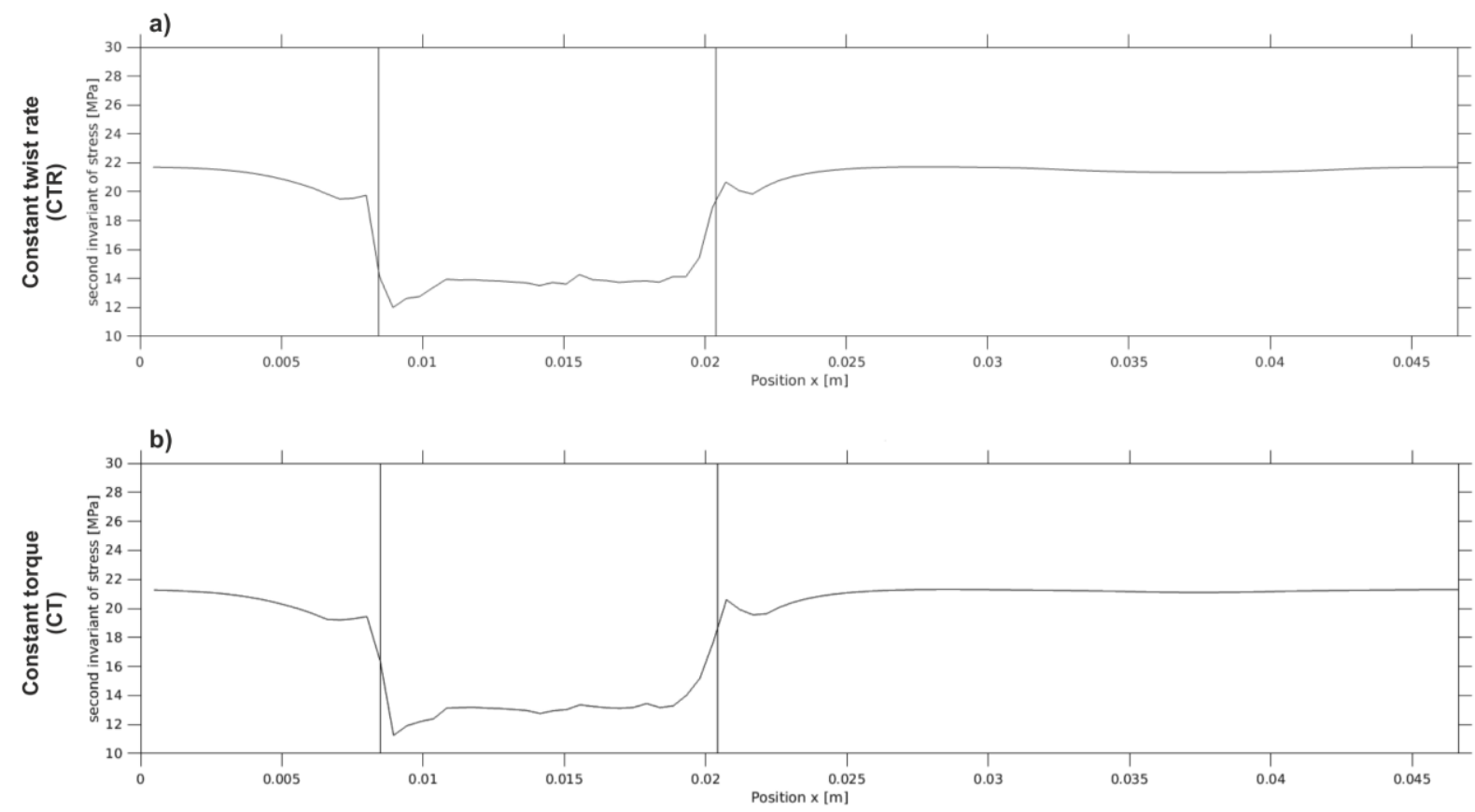

c)
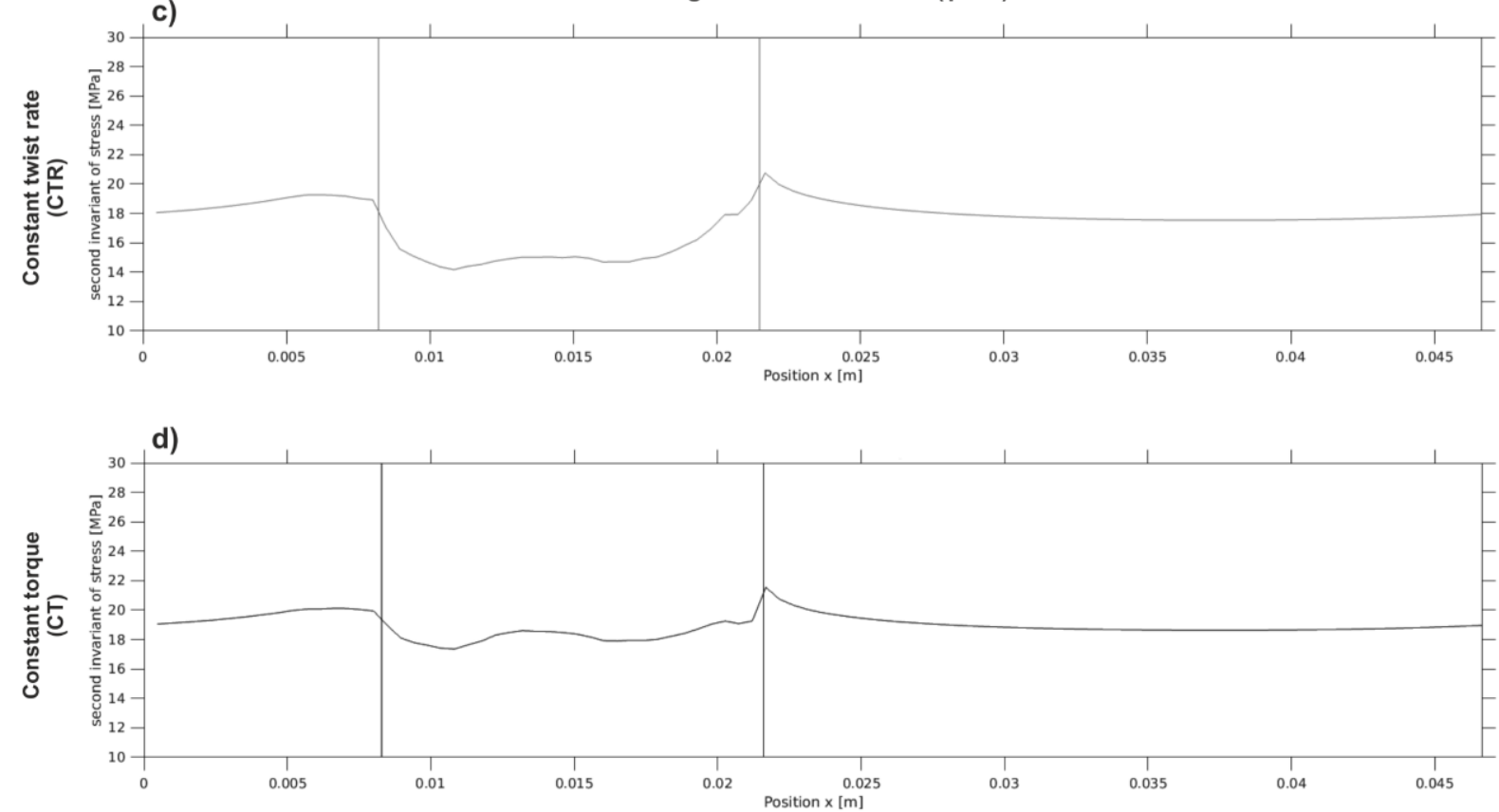

Fig. 16 a-d: Results of a modelling study assuming material parameters and experimental conditions as in the tests (Döhmann et al., subm.). Plotted are the profiles of the second invariant of stress across the outer surface of the sample cylinders; vertical lines are indicating the position of the Solnhofen limestone inclusion at the final bulk shear strain for low strain $(a, b)$ and high strain $(c, d)$. Note low shear stresses within the inclusion and stress maxima at the inclusion tips.

Here we employ 2D Cartesian models with periodic boundary conditions that have been benchmarked to experimental mechanical data. The gradient in flow stress reconstructed for sample CTR03 (Fig. 13) by means of dislocation density piezometry is in general accordance with results from numerical models (Fig. 16). In their study, Döhmann et al. (subm.) found a rapid stress drop, down to roughly far-field levels, within $2-3 \mathrm{~mm}$ from the inclusion tip. 
Numerical modeling was carried out by means of the geodynamic modeling software SLIM3D (Semi-Lagrangian Implicit Model for 3 Dimensions, Popov and Sobolev, 2008), which was originally intended for the study of lithospheric-scale processes (Brune, 2016) but has been applied to laboratory scale localization models as well (Cyprych et al., 2016). For the applied thermodynamically coupled conservation equations, see Popov and Sobolev, 2008. Experimentally derived (Schmid et al., 1980 and Rybacki et al., 2014) flow laws were used to model deformation of Carrara marble and Solnhofen limestone, and a straindependent viscous softening mechanism was implemented (Brune et al., 2014). Model-

610 derived profiles of the second invariant of stress along the inclusion and process zone at the cylinders' outer surface show local stress concentration at the inclusion tip decaying towards the matrix (Fig. 16). Stress concentration is significantly smaller than observed in the deformed samples but the general trend agrees with experimental results. For example, a nonlinear stress decay is observed with increasing distance from the inclusion towards the matrix irrespective of loading conditions. The weakening induced in the marble by the applied high stresses reduces its viscosity and leads to a progressive stress relaxation along the process zone with increasing bulk strain (compare Fig. 16a and c for constant twist rate and $16 \mathrm{~b}$ and $\mathrm{d}$ for constant torque experiments). Note that a stress peak at the inclusion tip is preserved in all cases and regardless of total strain (Table 3 and Fig. 16), as the viscosity contrast between the inclusion and the matrix surrounding it is still high. Fig. 16 also shows a quantitative comparison of stress distribution between constant stress and constant strain rate experiments, highlighting the absence of a substantial difference in the shape and magnitude of the area of enhanced stress.

The paleowattmeter introduced by Austin and Evans, (2007) allows relating grain size of dynamically recrystallized material to mechanical work rather than to flow stress alone. We applied the suggested scaling relationship (eq. 8, 9 in Austin and Evans, 2007) to our data. Using the measured grain sizes listed in Table 3 and the values of local strain rates derived from the strain markers (see section 4.2), the predicted concentration in stresses with respect to the far field equivalent stress is in the range 3-5, in good agreement with the paleopiezometric estimates (factor 2-4, depending on calibration, Table 3). The approach may also be used to predict the average recrystallized grain size for given differential stresses and strain rates. Resulting recrystallized grain sizes vary between 10-12 $\mu \mathrm{m}$ (far field stress) and 8-10 $\mu \mathrm{m}$ (up to a factor 4 stress concentration, the upper bound derived from paleopiezometry), in good accordance to what measured optically in the samples (Table 3). Taking into account the uncertainty of measured grain sizes and strain rates, we conclude that our experiments do not allow to resolve if the wattmeter yields more reliable results than the piezometer. It should be borne in mind, however, that our quantitative estimates are 
conducted on somehow transient microstructures, and the applicability of piezometric and wattmetric techniques to such conditions should be regarded as limited.

\subsection{Amount and geometry of strain localization}

Strain localization as indicated by strain markers increased as the process zone propagated into the Carrara matrix (Fig. 6a, b). However, localization remained unaffected by the different loading conditions. Within the process zone at low bulk strains Carrara marble is strongly twinned: thick, often tapered or bent twins are abundant, as are multiple twin sets within single crystals. Deformation twinning in calcite has been extensively studied in the past (e.g. Barber and Wenk, 1979; Wenk, 1985), and twin morphology and intensity (number of twins per $\mathrm{mm}$ ) are often used as stress-strain indicators (paleopiezometers) during low grade metamorphism (Ferrill, 1991; Ferrill et al., 2004; Rybacki et al., 2013 and Burkhard, 1993 for a review). At low temperatures and low stress, twinning on the e-plane

$650\{01-18\}$ may accommodate strain until hardening sets in due to the activity of only one independent slip system (Burkhard, 1993). At higher temperatures, dynamic recovery processes accommodate strain as observed in the high strain samples, CTR1 and CT1. Qualitatively, the morphology and distribution of twin sets does not display substantial differences between samples deformed at different loading conditions. Other microstructural expressions of localized viscous deformation in the process zone have been extensively presented (sections 4.3 and 4.4): variations in these latter between constant stress and constant strain rate samples are local and within measurement uncertainty. Strain partitioning into the process zone is clearly recognizable at low bulk strains of $\gamma \sim 0.3$ and continues progressively with increasing shear strain irrespective of loading conditions (Fig $6 b)$. Once weakening is completed with progressive strain, partitioning of shear strain into the localized shear zone saturates at a constant shear strain ratio between shear zone and bulk sample (Fig.6a). The slope in Fig. 6a defines the critical shear strain $\gamma_{c}$ required to complete weakening at a critical length of the process zone. Process zone length and shear strain gradient depend on viscosity contrast between strong host rock and weak shear zone and the weakening mechanism(s).

\subsection{Comparison to previous experimental work}

High temperature experimental deformation has been conducted extensively on rock-forming minerals to reproduce the processes occurring in natural shear zones. Since the introduction of the torsion setup in the Paterson gas deformation apparatus, a number of large strain studies have been performed on monophase materials, such as olivine (e.g. Bystricky et al., 2000; Hansen et al., 2012), calcite (Casey et al., 1998; Pieri et al., 2001a, b; Barnhoorn et al., 2004), quartz (e.g. Schmocker et al., 2003) or on multi-phase aggregates (e.g. Rybacki et al., 2003; Barnhoorn et al., 2005; Dimanov \& Dresen, 2005; Holyoke \& Tullis, 2006). 
Notably, although mechanical weakening of the deforming materials was described in all cases, localization of deformation at the sample scale was only observed in a small number of these studies, where it appeared to be favoured, e.g. by high initial strength contrast between phases (Holyoke and Tullis, 2006), by a switch in deformation mechanism in only one of the deforming phases, producing locally heterogeneous phase distribution (Barnhoorn et al., 2005) or in the case of imposed constant load (torque) boundary conditions (Hansen et al., 2012). This latter is in good agreement with what was theoretically predicted for the torsion geometry by several authors (Fressengeas and Molinari, 1987; Leroy and Molinari, 1992; Paterson, 2007) who, by means of linearized perturbation analysis, prescribe strain localization to be dependent on the applied boundary conditions: a small enough perturbation of one of the material properties is not expected to produce localization in a constant displacement rate setting even if strain weakening is observed, as opposed to a constant load setup in which localization is always favoured. However, it is important to point out that, as Fressengeas and Molinari (1987) also clarify in their contribution, linear perturbation analysis is carried out with the assumption of small deviations from homogeneity of the material properties: for larger perturbations the field equations cannot be linearized and the analytical solutions are much more complex. We argue that, in our experimental setting, the initial departure from a homogeneous stress distribution that is imposed to the system by the presence of a strong viscosity contrast is too large for the linear approximation to be valid. As a consequence, it can be inferred that, for bi- or multi-phase materials with sufficient viscosity contrast (as is often the case in nature), the expected influence of boundary conditions on localization is absent or minor.

\subsection{Implications for natural shear zones}

Our study shows that, in the presence of a material heterogeneity in an otherwise homogeneous medium, localized shear zones form regardless of the imposed loading conditions. Recent theoretical studies accompanied by integration of existing field data (Whipple Mountains core complex, southeast California; Platt and Behr, 2011a and Platt and Behr, 2011c), however, propose a theory for the development of viscous shear zone in the middle to lower crust in a stress-controlled environment. The authors concluded that the yield stress of the undeformed host rock controls the flow stress in the deforming shear zone. Consequently, a constant velocity boundary condition is always converted into a constant stress one. However, the theory is based on the assumption of steady-state deformation of a homogeneous crustal material. This premise seems to apply to a limited number of tectonic situations, but may not apply to channel flow (Beaumont et al., 2004) or the dynamic feedback between the brittle upper crust and the semibrittle to ductile lower part of the crust during syn- and inter-seismic periods (Trepmann and Stöckhert, 2003). In their review paper on shear zones in the mantle, Vauchez et al. (2012) also point out how the yield 
stress of a rock is strain rate dependent, where the strain rate itself is a function of shear zone width, so that the constant stress hypothesis is, in fact, intrinsically ambiguous. Numerous field and experimental studies conducted in the past decades have identified a number of mechanisms that are believed to trigger strain localization at the crustal scale, which can, in general terms, be summarized as the inherited presence of a rheological or structural heterogeneity, or the mentioned interaction with the seismogenic crust (for a review, see Vauchez et al., 2012). If the question still stands, of whether the initiation of shear zones is primarily dependent on the imposed loading conditions or on the activity of one of the aforementioned mechanisms, our results suggest that in the presence of, for example, an inherited rheological heterogeneity, shear zone formation is controlled by this latter while the applied boundary conditions appear to be of secondary importance.

\section{Conclusions}

We conducted high temperature torsion experiments to investigate the effect of loading conditions (constant twist rate or constant torque) on the initial and transient stages of strain localization in marble containing a weak material heterogeneity. The inclusion induced stress concentration halos in the stronger surrounding matrix resulted in strain partitioning into localized shear bands propagating into the marble with ongoing bulk deformation. Progressive localization is associated with strain weakening accommodated by dynamic recrystallization, CPO development and plastic deformation of relict grains within a process zone which is markedly different from the surrounding, relatively intact matrix. High temperature creep of marble is the dominant deformation mechanism at the applied experimental conditions, although evidences for coexisting brittle deformation are found regardless of loading conditions and total strain. The geometry, microstructural and textural features and evolution of the process zone are qualitatively and quantitatively comparable in constant torque and constant twist rate experiments.

Overall, our results suggest that the loading conditions do not significantly affect strain localization induced by the presence of a material heterogeneity during nucleation and transient evolution stages.

It should be kept in mind that the experimental setup poses some intrinsic limitations on the number of variables that can be investigated simultaneously. The effects that some of the latter (as the applied confining pressure, temperature or the presence of a second phase in the deforming matrix) might have on the weakening mechanisms and ultimately on the processes favouring strain localization are manifold and would require further investigation and a multidisciplinary approach (with experimental, field based and model based studies). 


\section{Acknowledgements}

We are grateful to Stefan Gehrmann for the preparation of experimental samples and thin sections. Further thanks are given to Anja Schreiber for FIB-foil cutting and Dr. Richard Wirth for the invaluable help with TEM analysis. Dr. Luca Menegon is gratefully thanked for fruitful discussion on the manuscript and the project in general. This project was founded by DFG grant GR 4468/2. M.D. and S.B. have been funded through the Helmholtz Young Investigators Group CRYSTALS (VH-NG-1132).

\section{References}

N. J. Austin, B. Evans, Paleowattmeters: A scaling relation for dynamically recrystallized grain size, In Geology, Volume 35, Issue 4, 2007, Pages 343-346, ISSN 0091-7613, http://dx.doi.org/10.1130/G23244A.1

F. Bachmann, R. Hielscher, H. Schaeben, Texture Analysis with MTEX - Free and Open Source Software Toolbox, In Solid State Phenomena, Volume 160, 2010, Pages 63-68, ISSN 1662-9779, http://doi.org/10.4028/www.scientific.net/SSP.160.63.

D. J. Barber, H. R. Wenk, Deformation twinning in calcite, dolomite and other rhombohedral carbonates, In Physics and Chemistry of Minerals, Volume 5, Issue 2, 1979, Pages 141-165, ISSN 1432-2021, https://doi.org/10.1007/BF00307550.

A. Barnhoorn, M. Bystricky, L. Burlini, K. Kunze, The role of recrystallisation on the deformation behaviour of calcite rocks: large strain torsion experiments on Carrara marble, In Journal of Structural Geology, Volume 26, Issue 5, 2004, Pages 885-903, ISSN 0191-8141, https://doi.org/10.1016/j.jsg.2003.11.024.

A. Barnhoorn, M. Bystricky, K. Kunze, L. Burlini, J.-P. Burg, Strain localisation in bimineralic rocks: Experimental deformation of synthetic calcite-anhydrite aggregates, In Earth and Planetary Science Letters, Volume 240, Issues 3-4, 2005, Pages 748-763, ISSN 0012-821X, https://doi.org/10.1016/i.epsl.2005.09.014.

C. Beaumont, R. A. Jamieson, M. H. Nguyen, S. Medvedev, Crustal channel flows: 1. Numerical models with applications to the tectonics of the Himalayan-Tibetan orogeny, In Journal of Geophysical Research: Solid Earth, Volume 109, Issue B6, 2004 ISSN 01480227, https://doi.org/10.1029/2003JB002809.

D. Bercovici, Plate generation in a simple model of lithosphere-mantle flow with dynamic selflubrication, In Earth and Planetary Science Letters, Volume 144, Issues 1-2, 1996, Pages 41-51, ISSN 0012-821X, https://doi.org/10.1016/0012-821X(96)00140-9. 
D. Bercovici, Generation of plate tectonics from lithosphere-mantle flow and void-volatile self-Iubrication, In Earth and Planetary Science Letters, Volume 154, Issues 1-4, 1998, Pages 139-151, ISSN 0012-821X, https://doi.org/10.1016/S0012-821X(97)00182-9.

D. Bercovici, S-I. Karato, Theoretical Analysis of Shear Localization in the Lithosphere, In Reviews in Mineralogy and Geochemistry, Volume 51, Issue 1, 2002, Pages 387-420, ISSN 1529-6466, http://dx.doi.org/10.2138/gsrmg.51.1.387.

D. Bercovici, The generation of plate tectonics from mantle convection, In Earth and Planetary Science Letters, Volume 205, Issues 3-4, 2003, Pages 107-121, ISSN 0012-821X, https://doi.org/10.1016/S0012-821X(02)01009-9.

M. Bestmann, K. Kunze, A. Matthews, Evolution of a calcite marble shear zone complex on Thassos Island, Greece: microstructural and textural fabrics and their kinematic significance, In Journal of Structural Geology, Volume 22, Issues 11-12, 2000, Pages 1789-1807, ISSN 0191-8141, https://doi.org/10.1016/S0191-8141(00)00112-7.

S. Brune, C. Heine, M. Pérez-Gussinyé, S. V. Sobolev, Rift migration explains continental margin asymmetry and crustal hyper-extension, In Nature Communications, Volume 5, Article 4014, 2014, http://dx.doi.org/10.1038/ncomms5014.

795 S. Brune, Rifts and rifted margins: A review of geodynamic processes and natural hazards, In J. C. Duarte \& W. P. Schellart, Eds.: Plate Boundaries and Natural Hazards, Geophysical monograph series, Volume 219, Pages 11-37, 2016, https://doi.org/10.1002/9781119054146.ch2.

H. Bunge, Texture analysis in material sciences: mathematical methods (1982), London: 800 Butterworths, pp. 593.

M. Burkhard, Calcite twins, their geometry, appearance and significance as stress-strain markers and indicators of tectonic regime: a review, In Journal of Structural Geology, Volume 15, Issues 3-5, 1993, Pages 351-368, ISSN 0191-8141, https://doi.org/10.1016/01918141(93)90132-T.

L. Burlini, D. Bruhn, High-strain zones: laboratory perspectives on strain softening during ductile deformation, In Geological Society, London, Special Publications, Volume 245, 2005, ISSN 2041-4927, http://sp.lyellcollection.org/content/245/1/1.

M. Bystricky, K. Kunze, L. Burlini, J.-P. Burg, High Shear Strain of Olivine Aggregates: Rheological and Seismic Consequences, In Science, Volume 290, Issue 5496, 2000, Pages 1564-1567, ISSN 1095-9203, http://science.sciencemag.org/content/290/5496/1564. 
M. Casey, K. Kunze, D. L. Olgaard, Texture of Solnhofen limestone deformed to high strains in torsion, In Journal of Structural Geology, Volume 20, Issues 2-3, 1998, Pages 255-267, ISSN 0191-8141, https://doi.org/10.1016/S0191-8141(97)00058-8.

D. Cyprych, S. Brune, S. Piazolo, J. Quinteros, Strain localization in polycrystalline material with second phase particles: Numerical modeling with application to ice mixtures, In Geochemistry, Geophysics, Geosystems, Volume 17, Issue 9, 2016, Pages 3608-3628, ISSN 1525-2027, https://doi.org/10.1002/2016GC006471.

J. H. P. De Bresser, C. J. Spiers, Slip systems in calcite single crystals deformed at 300$800^{\circ} \mathrm{C}$, In Journal of Geophysical Research: Solid Earth, Volume 98, Issue B4, 1993, Pages 6397-6409, ISSN 0148-0227, https://doi.org/10.1029/92JB02044.

J. H. P. De Bresser, Steady state dislocation densities in experimentally deformed calcite materials: Single crystals versus polycrystals, In Journal of Geophysical Research: Solid Earth, Volume 101, Issue B10, 1996, Pages 22189-22201, ISSN 2156-2202, http://dx.doi.org/10.1029/96JB01759.

825 J. H. P. De Bresser, J. L. Urai, D. L. Olgaard, Effect of water on the strength and microstructure of Carrara marble axially compressed at high temperature, In Journal of Structural Geology, Volume 27, Issue 2, 2005, Pages 265-281, ISSN 0191-8141, https://doi.org/10.1016/j.jsg.2004.10.002.

A. Dimanov, E. Rybacki, R. Wirth, G. Dresen, Creep and strain-dependent microstructures of 830 synthetic anorthite-diopside aggregates, In Journal of Structural Geology, Volume 29, Issue 6, 2007, Pages 1049-1069, ISSN 0191-8141, https://doi.org/10.1016/i.jsg.2007.02.010.

M. R. Drury, J. L. Urai, Deformation-related recrystallization processes, In Tectonophysics, Volume 172, Issues 3-4, 1990, Pages 235-253, ISSN 0040-1951, https://doi.org/10.1016/0040-1951(90)90033-5.

A. Ebert, M. Herwegh, A. Pfiffner, Cooling induced strain localization in carbonate mylonites within a large-scale shear zone (Glarus thrust, Switzerland), In Journal of Structural Geology, Volume 29, Issue 7, 2007, Pages 1164-1184, ISSN 0191-8141, https://doi.org/10.1016/j.jsg.2007.03.007.

D. A. Ferrill, Calcite twin widths and intensities as metamorphic indicators in natural lowtemperature deformation of limestone, In Journal of Structural Geology, Volume 13, Issue 6, 1991, Pages 667-675, ISSN 0191-8141, https://doi.org/10.1016/0191-8141(91)90029-I. D. A. Ferrill, A. P. Morris, M. A. Evans, M. Burkhard, R. H. Groshong, C. M. Onasch, Calcite twin morphology: a low-temperature deformation geothermometer, In Journal of Structural 
Geology, Volume 26, Issue 8, 2004, Pages 1521-1529, ISSN 0191-8141,

H. Fossen, G. C. G. Cavalcante, Shear zones - A review, In Earth-Science Reviews, Volume 171, 2017, Pages 434-455, ISSN 0012-8252, https://doi.org/10.1016/i.earscirev.2017.05.002.

C. Fressengeas, A. Molinari, Instability and localization of plastic flow in shear at high strain rates, In Journal of the Mechanics and Physics of Solids, Volume 35, Issue 2, 1987, Pages 185-211, ISSN 0022-5096, https://doi.org/10.1016/0022-5096(87)90035-4.

F. Fusseis, M. R. Handy, C. Schrank, Networking of shear zones at the brittle-to-viscous transition (Cap de Creus, NE Spain), In Journal of Structural Geology, Volume 28, Issue 7, 2006, Pages 1228-1243, ISSN 0191-8141, https://doi.org/10.1016/j.jsg.2006.03.022.

F. Fusseis, M. R. Handy, Micromechanisms of shear zone propagation at the brittle-viscous transition, In Journal of Structural Geology, Volume 30, Issue 10, 2008, Pages 1242-1253, ISSN 0191-8141, https://doi.org/10.1016/i.jsg.2008.06.005.

R. H. Groshong, O. A. Pfiffner, L. R. Pringle, Strain partitioning in the Helvetic thrust belt of eastern Switzerland from the leading edge to the internal zone, In Journal of Structural Geology, Volume 6, Issues 1-2, 1984, Pages 5-18, ISSN 0191-8141, https://doi.org/10.1016/0191-8141(84)90079-8.

M. Guillope, J. P. Poirier, Dynamic recrystallization during creep of single-crystalline halite: An experimental study, In Journal of Geophysical Research: Solid Earth, Volume 84, Issue B10, 1979, Pages 5557-5567, ISSN 0148-0227, https://doi.org/10.1029/JB084iB10p05557.

M. R. Handy, H. Stünitz, Strain localization by fracturing and reaction weakening - a

865 mechanism for initiating exhumation of subcontinental mantle beneath rifted margins, In Geological Society, London, Special Publications, Volume 200, 2002, Pages 387-407, ISSN 2041-4927, http://sp.lyellcollection.org/content/200/1/387.

L. N. Hansen, M.E. Zimmerman, A.M. Dillman, D.L. Kohlstedt, Strain localization in olivine aggregates at high temperature: A laboratory comparison of constant-strain-rate and constant-stress boundary conditions, In Earth and Planetary Science Letters, Volumes 333334, 2012, Pages 134-145, ISSN 0012-821X, https://doi.org/10.1016/i.epsl.2012.04.016.

R. Heilbronner, S. D. Barrett, Image analysis in earth sciences: microstructures and textures of earth materials. Berlin, Springer, 2014, http://public.eblib.com/choice/publicfullrecord.aspx?p=1082384. 
M. Herwegh, K. Kunze, The influence of nano-scale second-phase particles on deformation of fine grained calcite mylonites, In Journal of Structural Geology, Volume 24, Issue 9, 2002 , Pages 1463-1478, ISSN 0191-8141, https://doi.org/10.1016/S0191-8141(01)00144-4.

R. Hielscher, $H$. Schaeben, A novel pole figure inversion method: specification of the MTEX algorithm, In Journal of Applied Crystallography, Volume 41, Issue 6, 2008, Pages 10241037, https://doi.org/10.1107/S0021889808030112.

B. E. Hobbs, H.B. Mühlhaus and A. Ord, Instability, softening and localization of deformation, in Knipe, R. J. \& Rutter, E. H. (eds), 1990, Deformation Mechanisms, Rheology and Tectonics, Geological Society Special Publication No. 54, pp. 143-165.

T. Kenkmann, G. Dresen, Stress gradients around porphyroclasts: palaeopiezometric estimates and numerical modelling, In Journal of Structural Geology, Volume 20, Issues 2-3, 1998, Pages 163-173, ISSN 0191-8141, https://doi.org/10.1016/S0191-8141(97)00074-6.

R. Kilian, R. Heilbronner, H. Stünitz, Quartz grain size reduction in a granitoid rock and the transition from dislocation to diffusion creep, In Journal of Structural Geology, Volume 33, Issue 8, 2011, Pages 1265-1284, ISSN 0191-8141, https://doi.org/10.1016/j.jsg.2011.05.004.

Y. M. Leroy, A. Molinari, Stability of steady states in shear zones, In Journal of the Mechanics and Physics of Solids, Volume 40, Issue 1, 1992, Pages 181-212, ISSN 0022 5096, https://doi.org/10.1016/0022-5096(92)90310-X.

L. Menegon, H. Stünitz, P. Nasipuri, R. Heilbronner, H. Svahnberg, Transition from fracturing to viscous flow in granulite facies perthitic feldspar (Lofoten, Norway), In Journal of Structural Geology, Volume 48, 2013, Pages 95-112, ISSN 0191-8141, https://doi.org/10.1016/i.jsg.2012.12.004.

K. Michibayashi, D. Mainprice, The Role of Pre-existing Mechanical Anisotropy on Shear Zone Development within Oceanic Mantle Lithosphere: an Example from the Oman

900 Ophiolite, In Journal of Petrology, Volume 45, Issue 2, 2004, Pages 405-414, https://doi.org/10.1093/petrology/egg099.

L. G. J. Montési, G. Hirth, Grain size evolution and the rheology of ductile shear zones: from laboratory experiments to postseismic creep, In Earth and Planetary Science Letters, Volume 211, Issues 1-2, 2003, Pages 97-110, ISSN 0012-821X, https://doi.org/10.1016/S0012$\underline{821 \times(03) 00196-1 .}$.

M. S. Paterson, D.L. Olgaard, Rock deformation tests to large shear strains in torsion, In Journal of Structural Geology, Volume 22, Issue 9, 2000, Pages 1341-1358, ISSN 01918141, https://doi.org/10.1016/S0191-8141(00)00042-0. 
M. S. Paterson, Localization in rate-dependent shearing deformation, with application to torsion testing, In Tectonophysics, Volume 445, Issues 3-4, 2007, Pages 273-280, ISSN 0040-1951, https://doi.org/10.1016/i.tecto.2007.08.015.

M. Pieri, L. Burlini, K. Kunze, I. Stretton, D. L. Olgaard, Rheological and microstructural evolution of Carrara marble with high shear strain: results from high temperature torsion experiments, In Journal of Structural Geology, Volume 23, Issue 9, 2001 a, Pages 13931413, ISSN 0191-8141, https://doi.org/10.1016/S0191-8141(01)00006-2.

M. Pieri, K. Kunze, L. Burlini, I. Stretton, D.L. Olgaard, J.-P. Burg, H.-R. Wenk, Texture development of calcite by deformation and dynamic recrystallization at $1000 \mathrm{~K}$ during torsion experiments of marble to large strains, In Tectonophysics, Volume 330, Issues 1-2, 2001b, Pages 119-140, ISSN 0040-1951, https://doi.org/10.1016/S0040-1951(00)00225-0.

J. P. Platt, W. M. Behr, Lithospheric shear zones as constant stress experiments, In Geology, Volume 39, Issue 2, 2011a, Pages 127-130, ISSN 0091-7613, http://dx.doi.org/10.1130/G31561.1.

J. P. Platt, W. M. Behr, Grainsize evolution in ductile shear zones: Implications for strain localization and the strength of the lithosphere, In Journal of Structural Geology, Volume 33, Issue 4, 2011b, Pages 537-550, ISSN 0191-8141, https://doi.org/10.1016/i.jsg.2011.01.018.

J. P. Platt, W. M. Behr, Deep structure of lithospheric fault zones, In Geophysical Research Letters, Volume 38, Issue 24, 2011c, ISSN 0094-8276, https://doi.org/10.1029/2011GL049719.

J. P. Poirier, Shear localization and shear instability in materials in the ductile field, In Journal of Structural Geology, Volume 2, Issue 1, 1980, Pages 135-142, ISSN 0191-8141, https://doi.org/10.1016/0191-8141(80)90043-7.

935

A. A. Popov, S. V. Sobolev, SLIM3D: A tool for three-dimensional thermomechanical modeling of lithospheric deformation with elasto-visco-plastic rheology, In Physics of the Earth and Planetary Interiors, Volume 171, Issues 1-4, 2008, Pages 55-75, ISSN 0031 9201, https://doi.org/10.1016/i.pepi.2008.03.007.

G. Ranalli, Rheology of the Earth, Springer Science \& Business Media, 1995.

K. Regenauer-Lieb, D. A. Yuen, Modeling shear zones in geological and planetary sciences: solid- and fluid-thermal-mechanical approaches, In Earth-Science Reviews, Volume 63, 
Issues 3-4, 2003, Pages 295-349, ISSN 0012-8252, https://doi.org/10.1016/S0012-

K. Regenauer-Lieb, D. A. Yuen, Positive feedback of interacting ductile faults from coupling of equation of state, rheology and thermal-mechanics, In Physics of the Earth and Planetary Interiors, Volume 142, Issues 1-2, 2004, Pages 113-135, ISSN 0031-9201, https://doi.org/10.1016/j.pepi.2004.01.003.

950 A. Rogowitz, B. Grasemann, B. Huet, G. Habler, Strain rate dependent calcite microfabric evolution - An experiment carried out by nature, In Journal of Structural Geology, Volume 69, Part A, 2014, Pages 1-17, ISSN 0191-8141, https://doi.org/10.1016/i.jsg.2014.08.004.

A. Rogowitz, J. C. White, B. Grasemann, Strain localization in ultramylonitic marbles by simultaneous activation of dislocation motion and grain boundary sliding (Syros, Greece), In Solid Earth, Volume 7, 2016, Pages 355-366, https://doi.org/10.5194/se-7-355-2016.

E. H. Rutter, The influence of interstitial water on the rheological behaviour of calcite rocks, In Tectonophysics, Volume 14, Issue 1, 1972, Pages 13-33, ISSN 0040-1951, https://doi.org/10.1016/0040-1951(72)90003-0.

E. H. Rutter, Experimental study of the influence of stress, temperature, and strain on the dynamic recrystallization of Carrara marble, In Journal of Geophysical Research: Solid Earth, Volume 100, Issue B12, 1995, Pages 24651-24663, ISSN 2156-2202, http://dx.doi.org/10.1029/95JB02500.

E. Rybacki, M. S. Paterson, R. Wirth, G. Dresen, Rheology of calcite-quartz aggregates deformed to large strain in torsion, In Journal of Geophysical Research: Solid Earth, Volume 108, Issue B2, 2003, ISSN 0148-0227, https://doi.org/10.1029/2002JB001833.

E. Rybacki, R. Wirth, G. Dresen, High-strain creep of feldspar rocks: Implications for cavitation and ductile failure in the lower crust, In Geophysical Research Letters, Volume 35, Issue 4, 2008, ISSN 1944-8007, http://dx.doi.org/10.1029/2007GL032478.

E. Rybacki, B. Evans, C. Janssen, R. Wirth, G. Dresen, Influence of stress, temperature, and 970 strain on calcite twins constrained by deformation experiments, In Tectonophysics, Volume 601, 2013, Pages 20-36, ISSN 0040-1951, https://doi.org/10.1016/i.tecto.2013.04.021.

E. Rybacki, L. F. G. Morales, M. Naumann, G. Dresen, Strain localization during high temperature creep of marble: The effect of inclusions, In Tectonophysics, Volume 634, 2014, Pages 182-197, ISSN 0040-1951, https://doi.org/10.1016/i.tecto.2014.07.032. 
975 S. M. Schmid, M. S. Paterson, J. N. Boland, High temperature flow and dynamic recrystallization in carrara marble, In Tectonophysics, Volume 65, Issues 3-4, 1980, Pages 245-280, ISSN 0040-1951, https://doi.org/10.1016/0040-1951(80)90077-3.

S. M Schmid, M. Casey, J. Starkey, The microfabric of calcite tectonites from the Helvetic Nappes (Swiss Alps), In Geological Society, London, Special Publications, Volume 9, Issue 980 1, 1981, Pages 151-158, ISSN 2041-4927, http://sp.lyellcollection.org/content/9/1/151.

S. M. Schmid, R. Panozzo, S. Bauer, Simple shear experiments on calcite rocks: rheology and microfabric, In Journal of Structural Geology, Volume 9, Issues 5-6, 1987, Pages 747778, ISSN 0191-8141, https://doi.org/10.1016/0191-8141(87)90157-X.

M. Schmocker, M. Bystricky, K. Kunze, L. Burlini, H. Stünitz, J.-P. Burg, Granular flow and Riedel band formation in water-rich quartz aggregates experimentally deformed in torsion, In Journal of Geophysical Research: Solid Earth, Volume 108, Issue B5, ISSN 0148-0227, https://doi.org/10.1029/2002JB001958.

G. Schubert, D. L. Turcotte, P. Olson, Mantle convection in the Earth and planets, 2001, from Cambridge University Press.

990 P. J. Tackley, Mantle Convection and Plate Tectonics: Toward an Integrated Physical and Chemical Theory, In Science, Volume 288, Issue 5473, 2000, Pages 2002-2007, http://science.sciencemag.org/content/288/5473/2002.

J. H. Ter Heege, J. H. P. De Bresser, C. J. Spiers, The influence of dynamic recrystallization on the grain size distribution and rheological behaviour of Carrara marble deformed in axial 995 compression, In Geological Society of London, Special publications, Volume 200, 2002, Pages 331-353, ISSN 2041-4927, https://doi.org/10.1144/GSL.SP.2001.200.01.19.

A. Tommasi, M. Knoll, A. Vauchez, J. W. Signorelli, C. Thoraval, R. Logé, Structural reactivation in plate tectonics controlled by olivine crystal anisotropy, In Nature Geoscience, Volume 2, 2009, Pages 423-427, ISSN 1752-0908, http://dx.doi.org/10.1038/ngeo528.

1000 C. A. Trepmann, B. Stöckhert, Quartz microstructures developed during non-steady state plastic flow at rapidly decaying stress and strain rate, In Journal of Structural Geology, Volume 25, Issue 12, 2003, Pages 2035-2051, ISSN 0191-8141, https://doi.org/10.1016/S0191-8141(03)00073-7.

1005 A. Vauchez, A. Tommasi, D. Mainprice, Faults (shear zones) in the Earth's mantle, In Tectonophysics, Volumes 558-559, 2012, Pages 1-27, ISSN 0040-1951, https://doi.org/10.1016/i.tecto.2012.06.006. 
H. R. Wenk, Carbonates. In: Preferred orientation in deformed metals and rocks: an

1010 introduction to modern texture analysis. Academic press, 1985, Pages 361-384.

R. Wirth, Focused Ion Beam (FIB): applications in micro- and nanoanalysis in geosciences and applied mineralogy, In Practical Metallography, Volume 42, Issue 4, 2005, Pages 188205, https://doi.org/10.3139/147.100258. 